\title{
Pathways and variability at intermediate depths in the tropical Atlantic
}

\author{
C. Schmid ${ }^{\text {* }}$, Z. Garraffo ${ }^{\text {b }}$ E. Johns ${ }^{\mathrm{a}}$, and S. L. Garzoli ${ }^{\mathrm{a}}$
}

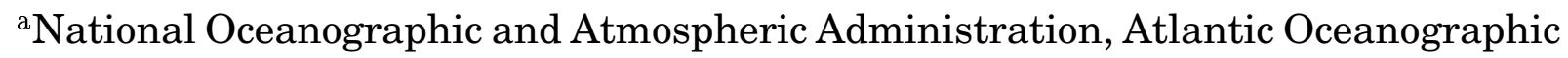
and Meteorological Laboratory, 4301 Rickenbacker Causeway, Miami, Florida 33149, USA

${ }^{b}$ Rosenstiel School of Marine and Atmospheric Science, University of Miami, Miami, Florida, USA

Oceanographic and meteorological data as well as model results are analyzed to study the pathways and the temporal variability of the intermediate depth (800$1100 \mathrm{~m})$ flow in the tropical Atlantic $\left(9^{\circ} \mathrm{S}\right.$ to $\left.7^{\circ} \mathrm{N}\right)$. The mean flow is dominated by zonal currents which interact with the western boundary current. These currents frequently experience reversals of the zonal and meridional flow. The primary focus in the analysis of the variability is on the region around $6^{\circ} \mathrm{S}$. The observations reveal temporal variability on mesoscale, annual and interannual time scales. Several westward propagating signals can be identified, with propagation velocities between 5 and $7 \mathrm{~cm} \mathrm{~s}^{-1}$. Two zonal length scales (500-700 $\mathrm{km}$ and more than $2000 \mathrm{~km}$ ) are observed. It is hypothesized that these are due to planetary waves. A comparative analysis of observations and model velocities reveals striking similarities in their time and length scales. Sample spectra of the model velocities show a dominant peak of the spectral energy density at a wave length between $500 \mathrm{~km}$ and $1100 \mathrm{~km}$. Additionally, a longer wave with a zonal wave length of about $5000 \mathrm{~km}$ is present, which can not be resolved by the spectral analysis. In the time space the spectral analysis for the zonal and meridional velocity reveals coinciding peaks at periods of 45 days, 66 days and one year. For the latter two periods the energy for the two velocity components are quite similar. An analytical planetary wave solution shows that a superposition of a mesoscale and an annual planetary wave is sufficient to reproduce a large part of the variability found in the observations and the model. The wave with an annual period is most likely due to the annual cycle of the wind field.

\section{INTRODUCTION}

In the Atlantic, the upper limb of the meridional overturning circulation (MOC) extends from the southern to the northern hemisphere requiring cross-equatorial

\footnotetext{
${ }^{*}$ Corresponding author. Tel. +1-305-361-4313. Email address: Claudia.Schmid@noaa.gov
} 
exchanges in both its upper and lower layers for continuity. The Antarctic Intermediate Water (AAIW) is the deepest component of the upper limb of the MOC and participates in this interhemispheric exchange. In the tropical Atlantic the AAIW layer is centered at about $800 \mathrm{~m}$.

Several earlier studies suggested that Subantarctic Mode Water (SAMW) is an important source water of the AAIW [McCartney, 1977; Molinelli, 1981; Keffer, 1985]. This was confirmed by Schmid et al. [2000] who showed that fresher water can be fed into the AAIW layer by wind-driven subduction of the low-salinity SAMW in the Polar Front Zone. Initially, the AAIW spreads eastward in the South Atlantic Current [Stramma and Peterson, 1990]. From here on the AAIW can either continue into the Indian Ocean, flow around the subtropical gyre of the South Atlantic, or follow interior pathways to the north [Schmid et al., 2000]. There are indications that each of these pathways carries about one third of the total eastward transport observed in the South Atlantic Current near the western boundary. The westward-flowing AAIW in the northern branch of the subtropical gyre splits up in the Santos Bifurcation just north of $30^{\circ} \mathrm{S}$ near the western boundary [Boebel et al., 1997, 1999b], where about two thirds of the AAIW flows south along the western boundary and recirculates in the subtropical gyre. The remaining one third turns northward as a western boundary current.

Transport estimates from several studies indicate that the strength of the western boundary current depends on the latitude [Fu, 1981; Holfort, 1994; Schott et al., 1998; Schmid et al., 2000]. Such changes can be partially attributed to zonal transports that feed into the boundary current or are fed by it. Another factor is the temporal variability of the boundary current itself. To achieve a better understanding of the water exchanges between the interior and the boundary current it is necessary to reach a better understanding of the interior flow pattern. Additionally, this knowledge is important since changes of the water properties along the way depend on the pathways the water parcels take. Stramma and Schott [1999] have developed a schematic map showing tropical and subtropical current distributions within the average depth range of AAIW in the Atlantic (Figure 1). Their schematic is based on circulation patterns derived from tracers and velocities across basin-wide zonal sections and direct synoptic velocity observations. The latter were mostly obtained near the western boundary. The schematic shows large east-west excursions of AAIW in the tropics which are related to the predominantly zonal currents in the interior of the tropics. Extensive meridional movements are primarily suggested along the boundaries of the basin.

The main feature of the circulation pattern envisioned by Stramma and Schott [1999], namely the predominance of several zonal currents in the interior, is supported by Schmid et al. [2001]. It is important to note that the Southern Intermediate Countercurrent (SICC) is missing in the schematic based on the observations by Schmid et al. [2001] since no trajectories were available in the region where this current is found. The Equatorial Intermediate Current is not shown in the lower panel of Figure 1 since the flow in the Antarctic Intermediate Water can be either eastward or westward, depending on the vertical structure of the equatorial jets [e.g. Gouriou et al., 1999]. Both studies imply a rather complicated pathway 

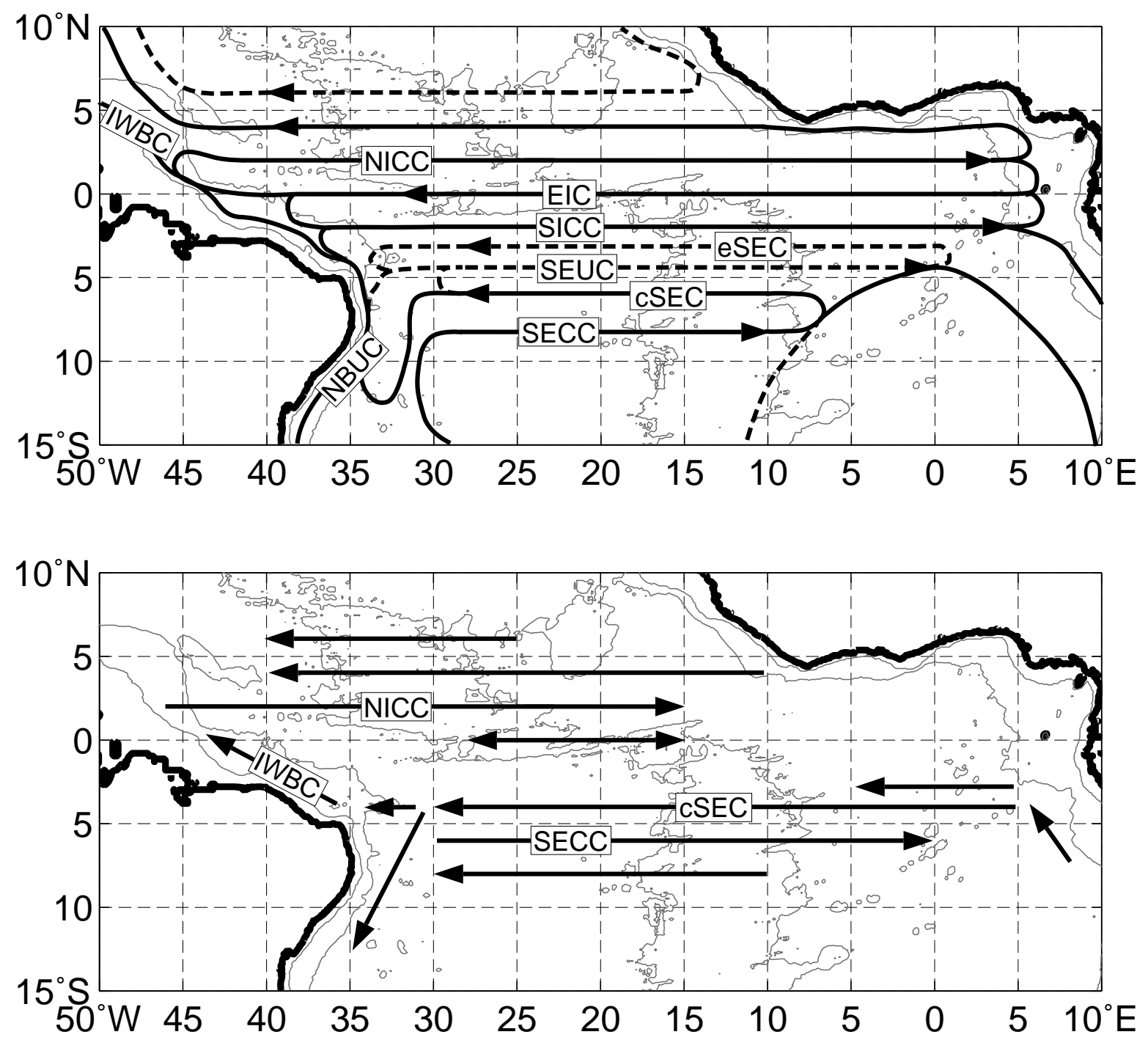

Figure 1. Schematic of the mean Antarctic Intermediate Water circulation. Top: adapted from Stramma and Schott [1999], for the layer between $500 \mathrm{~m}$ and $1200 \mathrm{~m}$. Bottom: based on Schmid et al. [2001], for the layer between $800 \mathrm{~m}$ and $1100 \mathrm{~m}$. The lower panel also indicates the reversal of the equatorial flow on annual time scales. The abbreviations are: IWBC = Intermediate Western Boundary Current, NBUC $=$ North Brazil Undercurrent, NICC $=$ Northern Intermediate Countercurrent, SICC $=$ Southern Intermediate Countercurrent, EIC = Equatorial Intermediate Current, eSEC = equatorial South Equatorial Current, SEUC = South Equatorial Undercurrent, cSEC = central South Equatorial Current, SECC = South Equatorial Countercurrent.

for AAIW as it traverses the tropical Atlantic (Figure 1). However, south of the SICC, Schmid et al. [2001] could not identify as many zonal currents as depicted by Stramma and Schott [1999]. Schmid et al. [2001] also noted that the latitudes of the mean eastward and westward currents do not always match the Stramma and Schott [1999] schematic. This difference may be due to the temporal variability of 
the flow, which can be more readily analyzed from time series derived with floats than from several consecutive hydrographic surveys.

For the eastern tropical South Atlantic, Warner and Weiss [1992] and Stramma and Schott [1999] suggested that a cyclonic gyre exists under the Angola Dome (the Angola Dome is centered at about $10^{\circ} \mathrm{S}, 5^{\circ} \mathrm{E}$ ), with southward flow near the eastern boundary (Figure 1, top). Stramma and Schott [1999] also show a southward current between this cyclonic gyre and the eastern boundary. Schmid et al. [2001] derived a different flow pattern in this region (Figure 1, bottom). Their analysis of three sections along $6^{\circ} \mathrm{S}$, the equator and $6^{\circ} \mathrm{N}$ confirmed earlier results that the minimum AAIW salinity decreases from east to west along $6^{\circ} \mathrm{S}$ and $6^{\circ} \mathrm{N}$ (their Figure 4). Along the equator the minimum salinity remains relatively constant and the minimum salinity near the eastern end of the $6^{\circ} \mathrm{S}$ section is the same as on the equator. This suggests that the equatorial AAIW may be fed directly by water coming from $6^{\circ} \mathrm{S}$. Such a pathway is partially supported by a mean current map for the 800-1100 dbar layer derived from profiling float velocities and individual trajectories [Schmid et al., 2001]. Two floats experienced northward drift for extended periods of time after their deployment at $6^{\circ} \mathrm{S}$, but they did not reach the equator. This may be due to a change in the flow field, or due to their periodic surfacing. Earlier studies suggested that a cyclonic gyre exists at intermediate depth with eastward flow at $4-5^{\circ} \mathrm{S}$ and southward flow along the eastern boundary [Warner and Weiss, 1992; Stramma and Schott, 1999]. The existence of such a flow pattern as a permanent feature can not be confirmed with the direct observations of the flow between 800 and $1100 \mathrm{~m}$, because of the northward flow observed with the two floats. It also seems unlikely that a cyclonic gyre exists in an annual mean since the mean flow derived at $4^{\circ} \mathrm{S}$ near the eastern boundary is westward (Figure 1, bottom) instead of eastward. A possible explanation for the difference in the schematics is that longer-periodic variabilities may be behind the absence of the cyclonic gyre in the more recent observations.

Several studies have shown that considerable spatial and temporal variability is superimposed on the mean currents in the tropical Atlantic. For example, seasonal reversals of the zonal flow at intermediate depth have often been observed close to the equator [e.g. Schott et al., 1998; Boebel et al., 1999a; Gouriou et al., 1999; Molinari et al., 1999; Richardson and Fratantoni, 1999; Schmid et al., 2001]. It has been proposed that planetary waves cause the variability. In data from profiling floats, Molinari et al. [1999] identified two current reversals that propagated westward with a speed of $15 \mathrm{~cm} \mathrm{~s}^{-1}$ at intermediate depths between the equator and $3^{\circ} \mathrm{N}$. Waves with the same phase speed, seasonal periodicity, a basin-wide length scale, and the characteristics of planetary waves are found in an eddyresolving, primitive equation model [Böning and Schott, 1993]. Poleward of $3^{\circ}$ latitude Schmid et al. [2001] found considerable variability (large standard deviations) in the zonal currents and they described seasonal reversals around $6^{\circ} \mathrm{S}, 10^{\circ} \mathrm{W}$.

Herein, we use a more extensive data set than was available to Schmid et al. [2001] to further examine the mean circulation of the water at intermediate depth. In addition to that, observational evidence for the temporal variability of the intermediate depth in the tropical Atlantic is described in more detail and the variabil- 


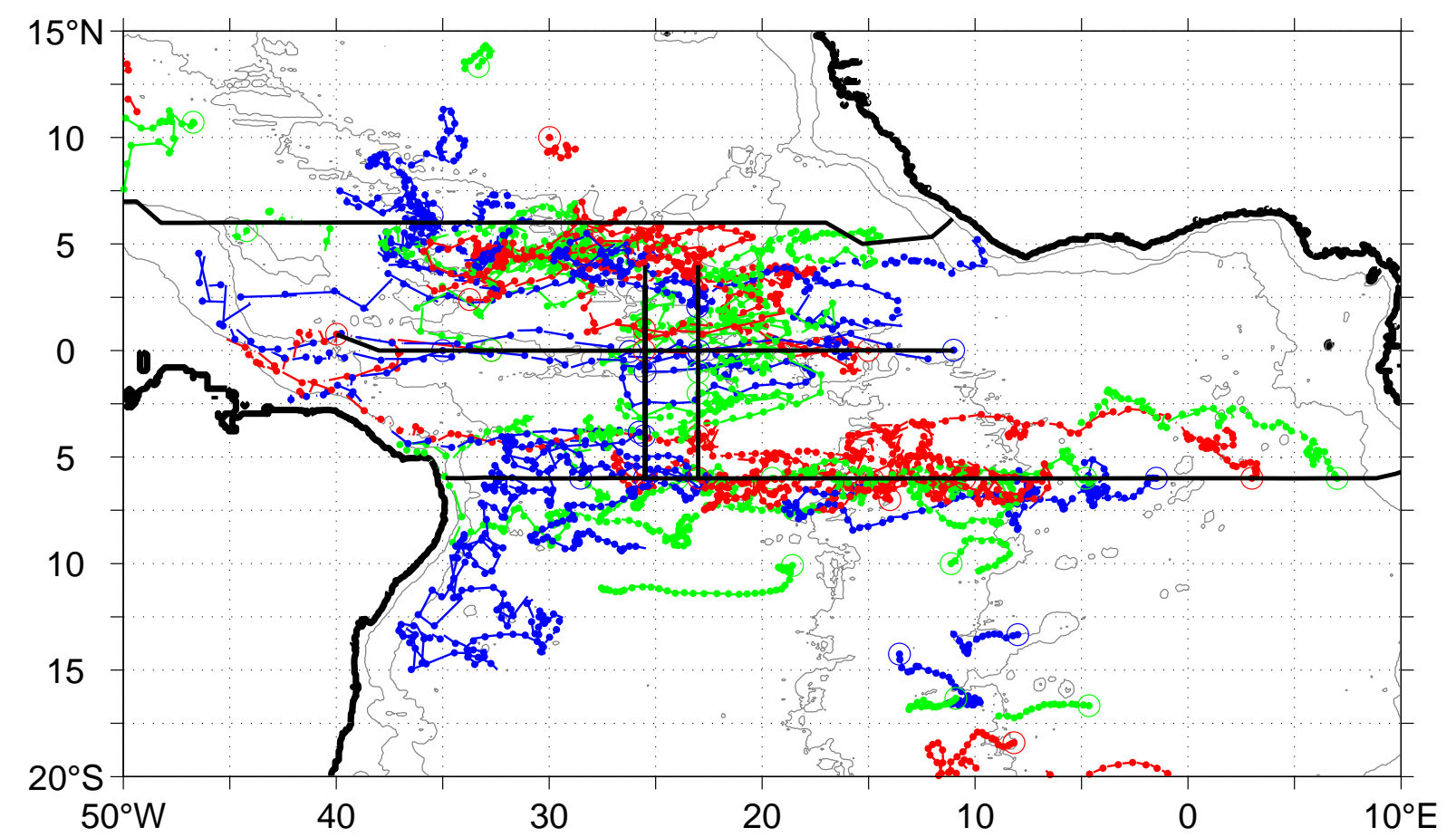

Figure 2. Trajectories of 50 profiling floats covering the time period from June 1997 until February 2002. Circles indicate the deployment positions. Only the submerged displacements between $800 \mathrm{dbar}$ and $1100 \mathrm{dbar}$ are shown. The grey lines indicate the hydrographic/LADCP sections used herein. They were obtained in the summer of 1997 and in January 2000. The isobaths are 1000 and $4000 \mathrm{~m}$.

ity at $6^{\circ} \mathrm{S}$ is analyzed on the basis of the equations for planetary waves and a numerical model. The study is structured as follows. Section 2 describes the data used in this work. In Section 3, the scales of the horizontal currents and the spreading of the AAIW are addressed. In Section 4 the temporal variability of the flow around $6^{\circ} \mathrm{S}$ and the underlying causes are considered. We conclude with a summary.

\section{DATA AND METHODS}

The Lagrangian measurements used in this study are from 50 profiling floats. The trajectories (Figure 2) cover the time period June 1997 to February 2002. Seventeen of the floats were launched in the summer of 1997 along two zonal sections, at the equator and at $6^{\circ} \mathrm{S}$. Twelve floats were deployed in January 2000 along three cross-equatorial sections, at $28^{\circ} \mathrm{W}, 25.5^{\circ} \mathrm{W}$ and $23^{\circ} \mathrm{W}$. The remaining 21 floats were deployed in the tropical Atlantic between December 2000 and September 2001, as part of the global ARGO project.

Profiling floats are designed to drift at a pre-selected depth, profile as they return to the surface after a preset time, remain at the surface to transmit their data to a satellite and then return to the drift depth. The subsurface periods of these profiling floats are between 8 and 10 days long, and the surface intervals range from 13 hours to 1 day. Because of the regular surfacing, the submerged trajectories 
are not continuous and care must be used when interpreting pathways from the floats (i.e., the effects of surface drift must be considered, see Schmid et al., 2001, for example).

The floats used in this study were ballasted to be neutrally buoyant at about $1000 \mathrm{dbar}$. The drifting depths of the 1997 floats ascended by 100 to $200 \mathrm{dbar}$ in the first 150 to 200 days of the trajectories [Schmid et al., 2001]. The 2000/2001 floats remained within 50 dbar of their target pressure, except for those that ran aground on the shelf. Only those trajectory segments with drift pressures between 800 and 1100 dbar are considered in this study.

The vertical scales of the horizontal currents will be addressed using lowered Acoustic Doppler Current Profiler (LADCP) data from two cruises. The locations of the used sections are shown in Figure 2. The LADCP is mounted on a rosette with the Conductivity Temperature Depth (CTD) sensors and provides profiles of horizontal currents. Comparisons with other direct velocity observations indicate that LADCP uncertainties are on the order of $2 \mathrm{~cm} \mathrm{~s}^{-1}$ [Hacker et al., 1996]. Fischer and Visbeck [1993] estimated that the error of LADCP data is about $5 \mathrm{~cm} \mathrm{~s}^{-1}$. Herein we will assume that the measurement error is about $5 \mathrm{~cm} \mathrm{~s}^{-1}$.

Velocity fields from a high resolution simulation with the Miami Isopycnic Coordinate Ocean Model (MICOM) will be used to further interpret the observations. This model is well documented in the literature. For a review, the reader is referred to Bleck et al. [1992] and Bleck and Chassignet [1994]. The fundamental reason for modeling ocean flow in density coordinates is that this system suppresses the diapycnal component of numerically caused dispersion of material and thermodynamic properties, such as temperature and salinity. The computational domain of the simulation employed here is the north and equatorial Atlantic Ocean basin from $28^{\circ} \mathrm{S}$ to $65^{\circ} \mathrm{N}$, including the Caribbean Sea and the Gulf of Mexico. The horizontal grid ( $6 \mathrm{~km}$ on average) is defined on a Mercator projection with resolution given by $1 / 12^{\circ} \times 1 / 12^{\circ} \cos (\phi)$, where $\phi$ is the latitude. The high horizontal grid resolution drastically improved the model's behavior in comparison to that of previous coarse-resolution simulations. The major improvements are: a) a correct Gulf Stream separation [Chassignet and Garraffo, 2001], and b) higher eddy activity. The bottom topography is derived from a digital terrain data set with 5' latitudelongitude resolution (ETOPO5). The vertical density structure is represented by 15 isopycnic layers, topped by an active bulk Kraus-Turner surface mixed layer that exchanges mass and properties with the isopycnic layers underneath. The vertical discretization was chosen to provide maximum resolution in the upper part of the ocean. Open ocean boundaries are treated as closed, but are outfitted with $3^{\circ}$ buffer zones in which temperature and salinity are linearly relaxed toward their seasonally varying climatological values [Levitus, 1982], with damping/relaxation time from 5 days at the wall to 30 days at the inner edge of the buffer zone. The buffer zones restore the temperature and salinity fields to climatology in order to approximately recover the vertical shear of the currents through geostrophic adjustment. The model is forced with the monthly climatology from the 1979-1999 ECMWF reanalysis. The fields used in the forcing are wind stress vector, wind velocity, surface radiation, specific humidity, air temperature, and precipitation (from COADS, 
Da Silva et al., 1994). The heat flux is calculated using bulk formulae from surface radiation, air temperature, specific humidity, wind speed and model SST. The fresh water flux consists of E-P (evaporation obtained from wind speed, specific humidity and model SST minus precipitation from COADS), plus a small relaxation to observed surface salinity. The model has been integrated for 6 years and our analysis focuses on the final 2 years.

Spatial and temporal spectra are presented in Section 4. Both types of spectra were essentially derived in the same way. The raw spectrum is estimated and averaged over frequency (wave number) bands of varying widths. The width of these bands, the degrees of freedom and the confidence limits depend on the frequency (wave number) itself. This method yields smaller error bars at the higher frequencies (wave numbers), where the spectral energy density is smaller. At low frequencies (wave numbers) the band-averaged spectrum is the same as the spectrum before band-averaging.

\section{LARGE SCALE FLOW PATTERNS}

\subsection{Vertical and horizontal structure}

Schmid et al. [2001] found, using an equatorial LADCP section, that the zonal flow at the equator between $500 \mathrm{~m}$ and more than $1000 \mathrm{~m}$ seemed to be nearly uniform between $40^{\circ} \mathrm{W}$ and $10^{\circ} \mathrm{W}$ during the summer of 1997 , both in the vertical and in the zonal direction (Figure 3, top). The vertical distance between maximum eastward and westward flow along this section varies between 300 and $700 \mathrm{~m}$. This range is quite similar to the range of 400-600 $\mathrm{m}$ published elsewhere [Ponte et al., 1990; Böning and Schott, 1993; Schott et al., 1998; Molinari et al., 1999; Gouriou et al., 1999; Gouriou et al., 2001; Send et al., 2002]. Some of the earlier observations show that quite small vertical extents of the jets can be found at depths that include the AAIW layer (e.g. in a June 1991 profile presented by Böning and Schott, 1993), which makes opposing zonal flow within the AAIW layer possible.

Some features can be traced throughout most of the section (Figure 3, top). Examples are the westward jets near 1000 and $1500 \mathrm{~m}$, the eastward jets near 400 and $1600 \mathrm{~m}$, as well as the eastward anomaly (only two profiles show very weak westward flow) near $1250 \mathrm{~m}$. All of these jets extend over more than $25^{\circ}$ in longitude. Even though the station spacing is relatively large $\left(2-7^{\circ}\right)$ we are confident that a higher zonal resolution would yield a similar value. This result indicates that the zonal extent of the jets may sometimes be significantly larger than suggested in earlier studies, which could only show that the zonal extent is at least $10^{\circ}$ of longitude in all three oceans [Ponte and Luyten, 1990a; Ponte and Luyten, 1990b; Gouriou et al., 2001]. The section also reveals a longitudinal dependence of the depth of the jets.

The meridional velocity on the equator does not reveal a preference for northward or southward flow in the AAIW layer (Figure 3, bottom). The zonal extent of the areas with north- or southward flow is mostly about $550 \mathrm{~km}$. In addition, except for the two profiles near $25^{\circ} \mathrm{W}$ quite small meridional velocities were recorded in this layer. Between the two profiles the sign of the meridional velocity changes 

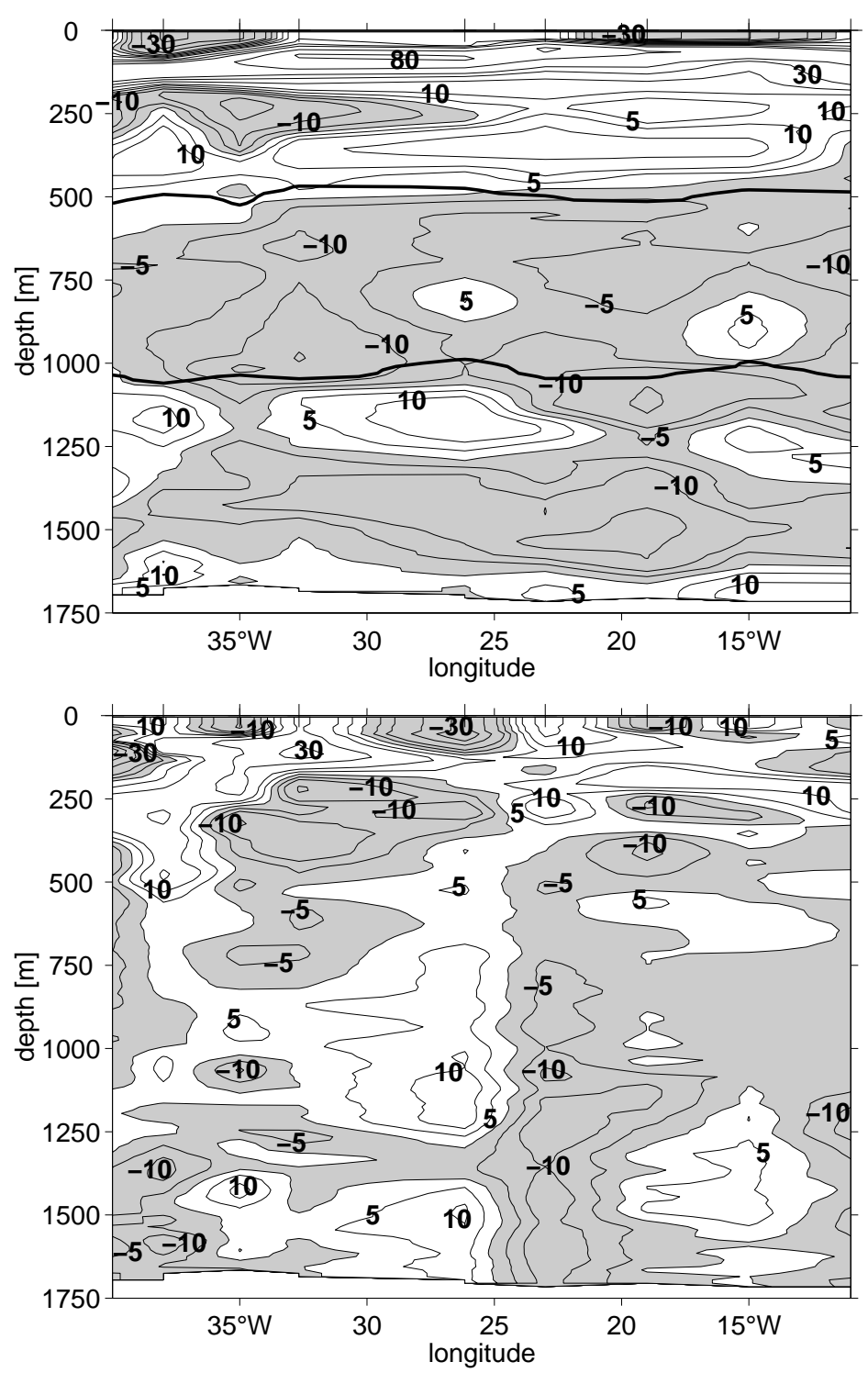

Figure 3. Equatorial velocity in the summer of 1997. For the location of the section see Figure 2. Top: zonal component. Bottom: meridional component. The thick lines in the top panel indicate the Antarctic Intermediate Water layer, bounded by the isopycnals $\sigma_{0}$ $=27.1 \mathrm{~kg} \mathrm{~m}^{-3}$ and $\sigma_{0}=27.45 \mathrm{~kg} \mathrm{~m}^{-3}$ (these isopycnals follow approximately the isohaline $34.6 \mathrm{psu}$ ). Tic marks at the top of each panel indicate the station locations. Negative values (grey shading) denote westward/southward flow.

throughout most of the water column, and the sign of the zonal velocity around $250 \mathrm{~m}$ changes as well.

Away from the equator a different flow pattern is observed. Along zonal sections at $6^{\circ} \mathrm{S}$ and $6^{\circ} \mathrm{N}$ the flow at most depths alternates several times between eastward and westward (Figure 4). The width of the flow bands is on the order of 5 to $10^{\circ}$ longitude. Similar scales govern the meridional velocity (Figure 5). These changes of direction often affect a large part of the water column between 300 and $1500 \mathrm{~m}$. 

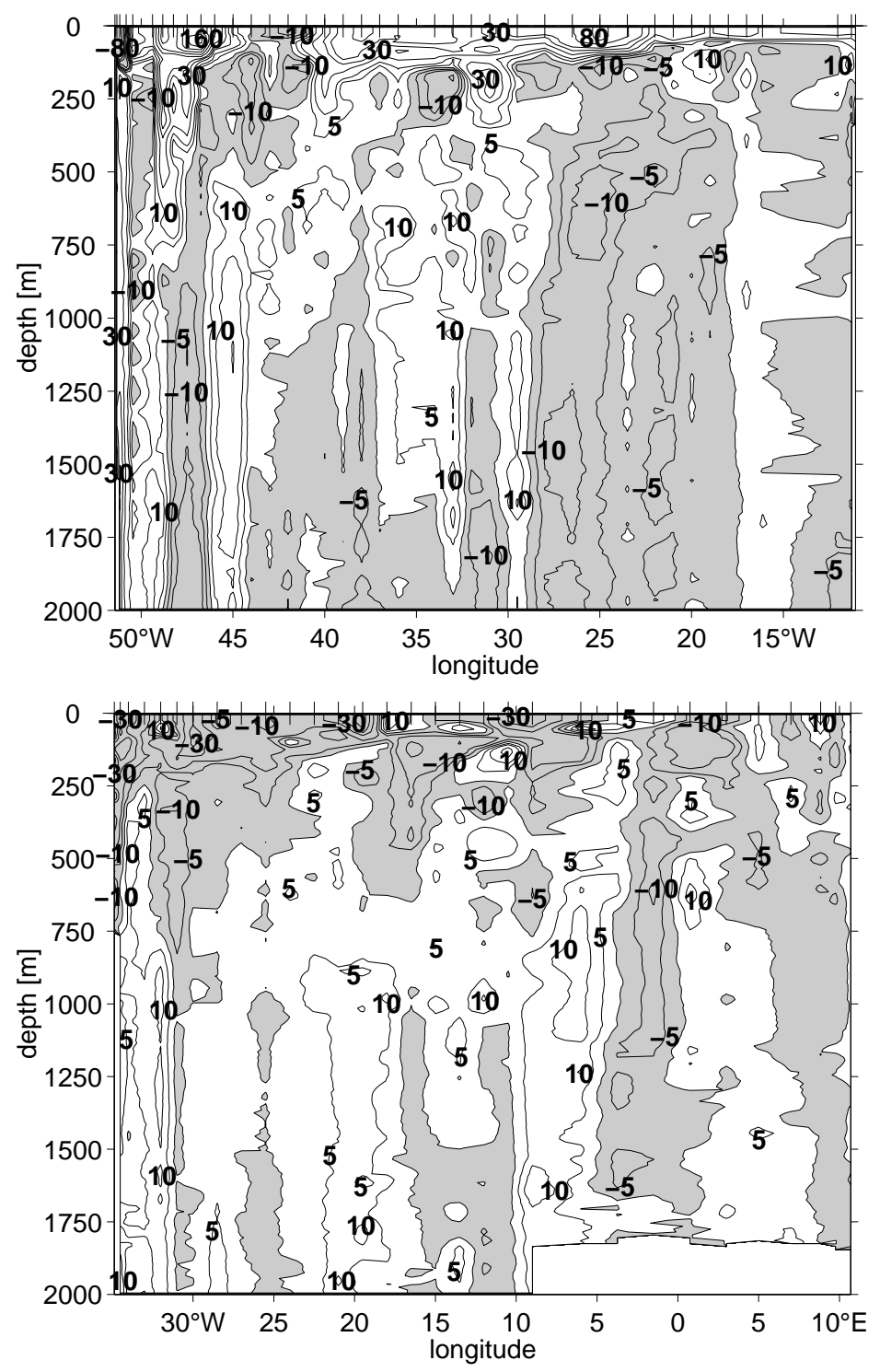

Figure 4. Zonal velocity in the summer of 1997. For the location of the section see Figure 2. Top: at $6^{\circ} \mathrm{N}$. Bottom: at $6^{\circ} \mathrm{S}$. Tic marks at the top of each panel indicate the station locations. Negative values (grey shading) denote westward flow.

With respect to the AAIW layer $(500$ to $1100 \mathrm{~m}$ ), the zonal and meridional flow at each profile is mostly in the same direction if only those velocities that exceed the measurement error $\left( \pm 5 \mathrm{~cm} \mathrm{~s}^{-1}\right)$ are taken into account. Exceptions of this can be seen, for example, between $35^{\circ} \mathrm{W}$ and $40^{\circ} \mathrm{W}$ (Figure 5 , top).

The difference in the vertical scales at different latitudes becomes more apparent in the meridional sections across the equator (Figure 6). In the equatorial band, within $1.5^{\circ}$ of the equator, the vertical scales are often smaller than outside of the equatorial band. In the vertical direction eastward or westward currents on the equator mostly do not extend over more than $600 \mathrm{~m}$, and if they do, then they reveal several maxima and minima. For example, at $23^{\circ} \mathrm{W}$ the eastward current 

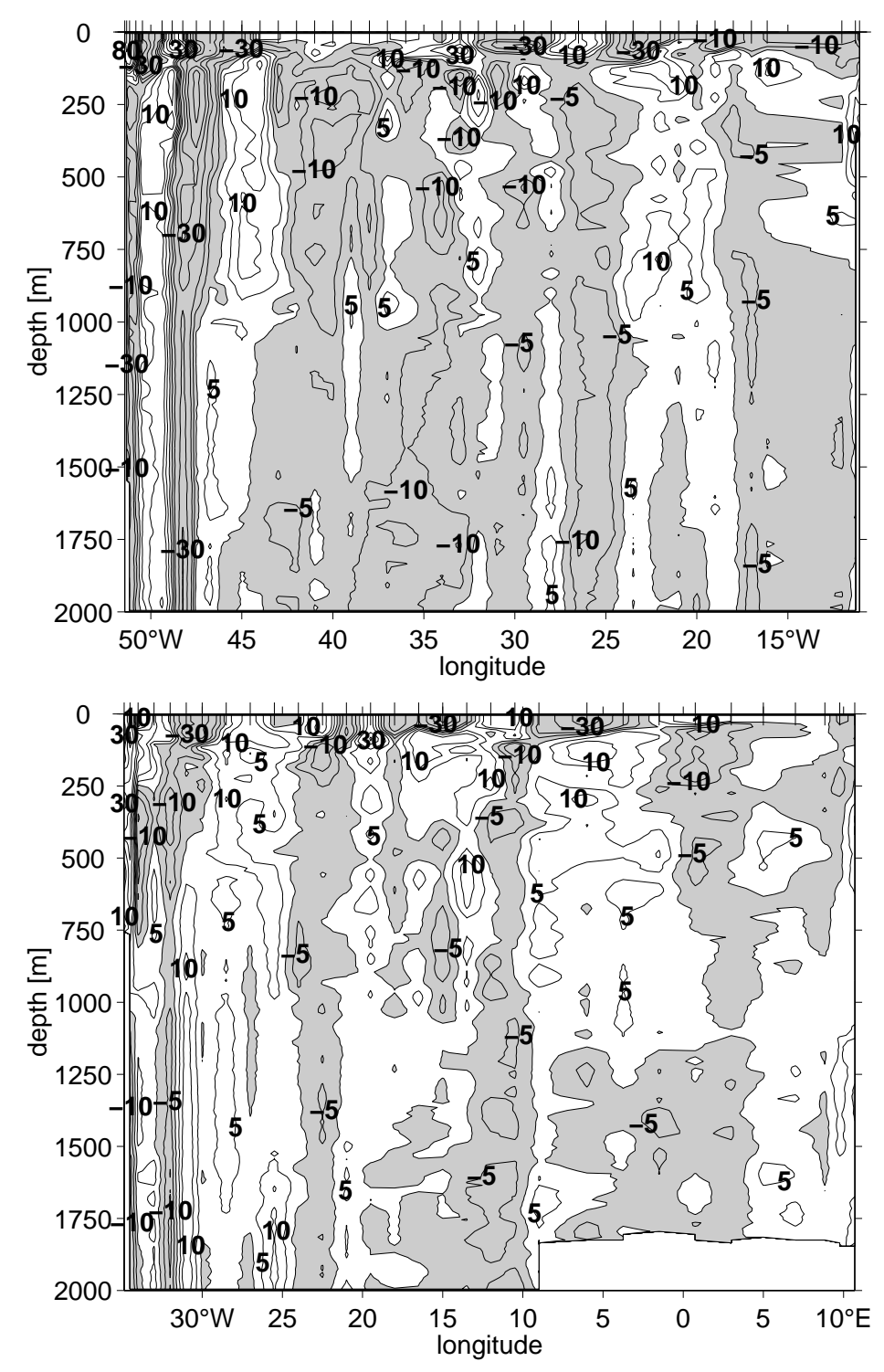

Figure 5. Meridional velocity in the summer of 1997. For the location of the section see Figure 2. Top: at $6^{\circ} \mathrm{N}$. Bottom: at $6^{\circ} \mathrm{S}$. Tic marks at the top of each panel indicate the station locations. Negative values (grey shading) denote southward flow.

extends over about $1000 \mathrm{~m}$, but three relative extreme values exist (centered at 1000,1250 and $1700 \mathrm{~m}$ ). Away from the equator the subthermocline currents typically extend over $1500 \mathrm{~m}$ or more (e.g. the eastward NICC and SICC centered around $1-2^{\circ}$ north and south of the equator, the westward current north of the $\mathrm{NICC}$ at $23^{\circ} \mathrm{W}$, the westward cSEC between 3 and $5^{\circ} \mathrm{S}\left(2^{\circ}\right.$ is a typical meridional scale of the off-equatorial currents), and the eastward SECC farther south). The South Equatorial Undercurrent (SEUC) (at 4 to $5^{\circ} \mathrm{S}$ ) is confined to the thermocline in both sections. This current separates the cSEC at the surface from the cSEC at intermediate depth. At $23^{\circ} \mathrm{W}$ the SEUC extends farther south as at $25.5^{\circ} \mathrm{W}$ and is almost joined with the SECC identified at intermediate depth. In the AAIW layer 

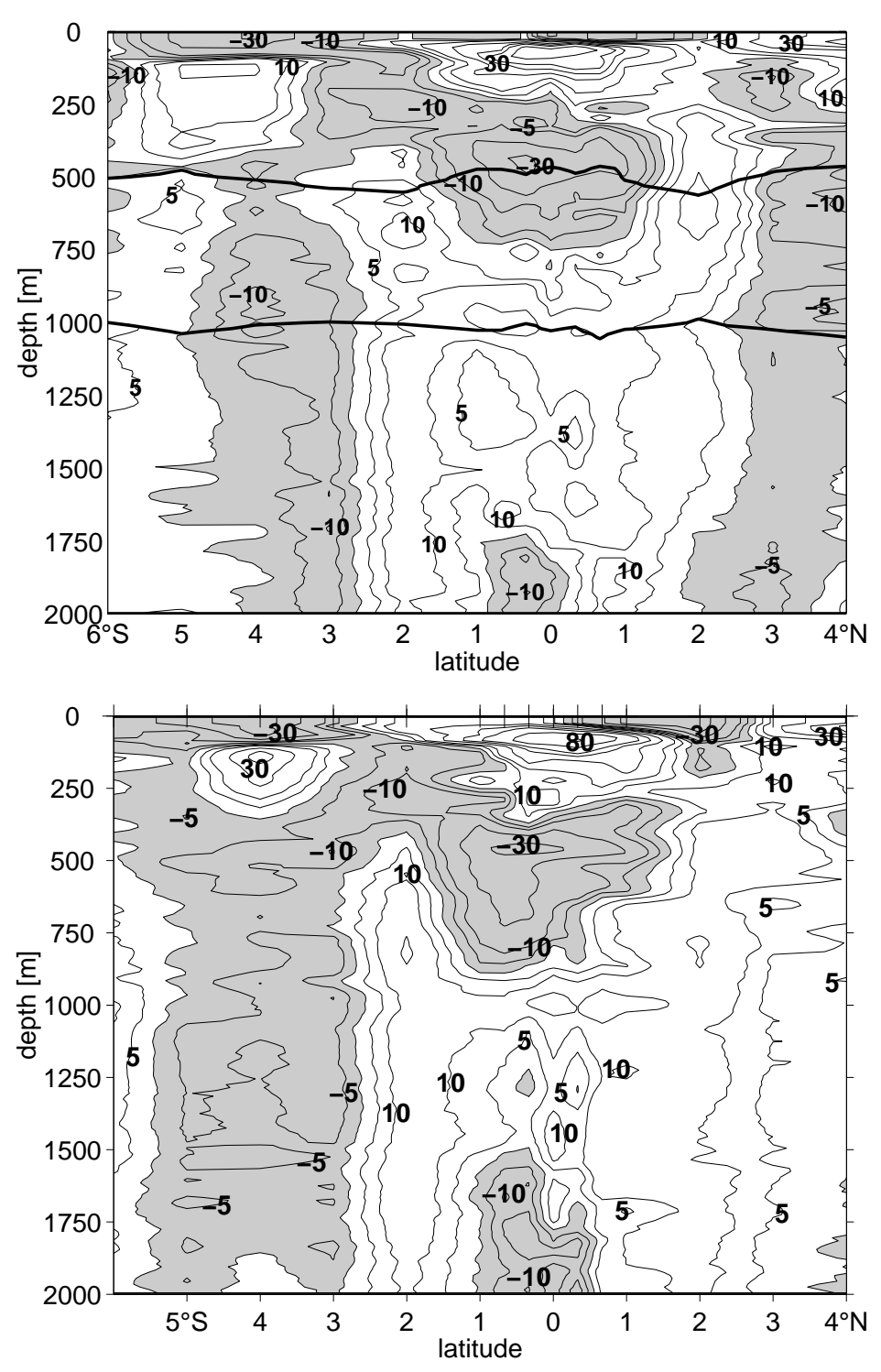

Figure 6. Zonal velocity in January 2000. For the location of the section see Figure 2. Top: taken in January $17-20$ at $23^{\circ} \mathrm{W}$. Bottom: taken in January $13-16$ at $25.5^{\circ} \mathrm{W}$. The thick lines in the top panel indicate the Antarctic Intermediate Water layer, bounded by the isopycnals $\sigma_{0}=27.1 \mathrm{~kg} \mathrm{~m}^{-3}$ and $\sigma_{0}=27.45 \mathrm{~kg} \mathrm{~m}^{-3}$ (these isopycnals follow approximately the isohaline $34.6 \mathrm{psu}$ ). Tic marks at the top of each panel indicate the station locations. Negative values (grey shading) denote westward flow.

the two sections, which were taken within one week, show an interesting feature in the equatorial band. In the eastern section $\left(\right.$ at $\left.23^{\circ} \mathrm{W}\right)$ the upper half of the layer experienced westward flow and the lower half of the layer experienced eastward flow, whereas in the western section (at $25.5^{\circ} \mathrm{W}$ ) most of the AAIW layer is governed by westward flow. 


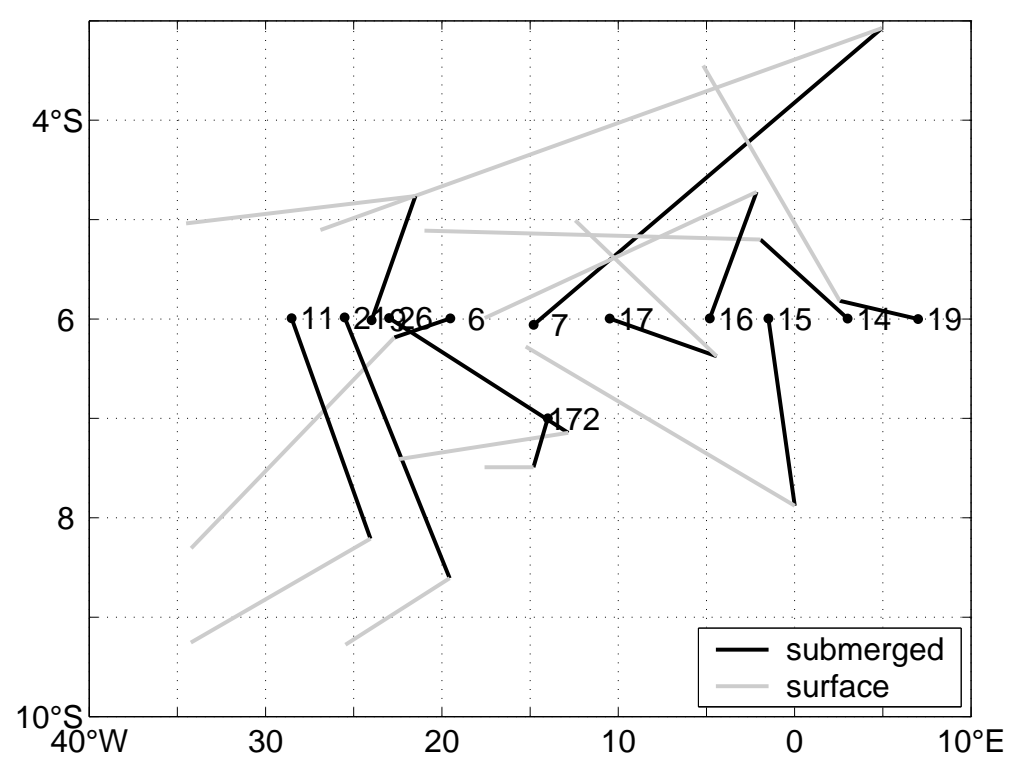

Figure 7. The total submerged and surface displacements of profiling floats deployed between $7^{\circ} \mathrm{S}$ and $5^{\circ} \mathrm{S}$ are shown. The numbers adjacent to the staring points (marked by dots) give the float numbers. For floats 6 to 19 the considered time periods vary vary between 2 (float 19) and 5 years (float 7). Float 172 was deployed at a later time and the considered time period was about half a year.

\subsection{Interior pathways.}

Several interesting features stand out in the trajectory plot (Figure 2). First, in general there appears to be almost no communication between the area south of about $3^{\circ} \mathrm{S}$ and the equator, i.e. the floats which were deployed south of $3^{\circ} \mathrm{S}$ tend to stay south of this latitude as long as they remain in the interior ocean. While this is not very obvious in Figure 2 , specifically between $20^{\circ} \mathrm{W}$ and $26^{\circ} \mathrm{W}$, it is clearly visible in the individual trajectories (not shown) and in the total displacements of the floats which will be discussed in what follows.

The total displacements at the surface and at depth for floats that were deployed within one degree of $6^{\circ} \mathrm{S}$ are shown in Figure 7. The displacements were estimated for the part of the trajectory that is fully within $34^{\circ} \mathrm{W}$ and $8^{\circ} \mathrm{E}$ and remained in the given pressure range of 800 to 1100 dbar during the submerged drift. The longitudinal bounds were chosen to exclude the effects of the boundary currents. The overall displacement vectors show that most floats deployed around $6^{\circ} \mathrm{S}$ either moved southward or did not make any significant northward progress. In contrast to this the floats deployed on or north of the equator often drift northward in the interior (some examples are presented in Figure 8, more details are given below). A separation of the drift into surface and submerged components can explain why the floats deployed at $6^{\circ} \mathrm{S}$ stay close to that latitude, as long as they are in the interior.

For the total surface drifts a quite clear pattern emerges. Floats deployed east of $12^{\circ} \mathrm{W}$ typically experienced a total northward surface drift. The only exception of this occurs for float 16, whose total surface drift is southward. All of the floats 

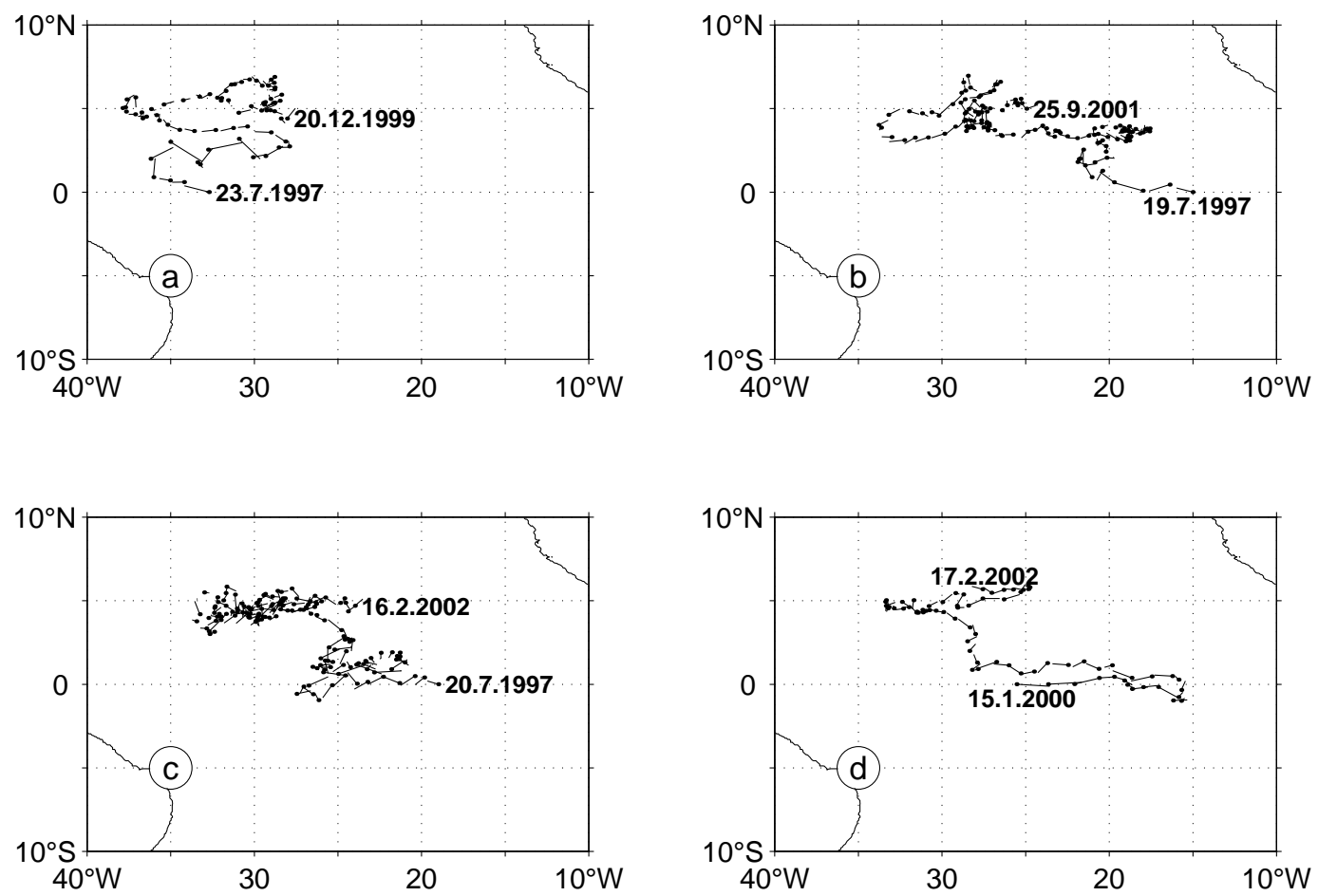

Figure 8. Examples for profiling floats that move meridionally in the interior. The start and end dates are given.

deployed west of $12^{\circ} \mathrm{W}$ experienced a total southward surface displacement. The latter can be linked to the influence of the Ekman drift. In this region the trade winds are more zonal than in the eastern region, which yields a larger southward component of the Ekman drift. The predominance of northward surface drift in the east can not be explained with the Ekman theory. Considering the southeast trades one would expect southwestward to westward surface flow. It seems likely that the geostrophic flow of the Angola Gyre, with its northward branch between the Greenwich Meridian and $10^{\circ} \mathrm{W}$, is strong enough to overcompensate the meridional component of the Ekman drift.

At intermediate depth northward and southward total displacements are observed as well, but a separation into an eastern and western regime is not possible (Figure 7). Nearly half of the $6^{\circ} \mathrm{S}$ floats (five out of twelve) experienced a net northward submerged drift. The other floats experienced a net southward submerged drift. This agrees with the existence of alternating meridional flow at intermediate depth in the zonal sections (Figure 5). The submerged meridional displacement of each float amounts to less than $3^{\circ}$, which means that none of the floats indicate that an interior connection between $6^{\circ} \mathrm{S}$ and the equator exists. This is mirrored in Figure 9 (for details on this figure see section "Semi-annual means of the velocity") where the mean meridional velocities in the interior are mostly insignificant and the standard deviation is quite large. The only exceptions of the prevalence of small means are restricted to bins with few observations (less than 15). These characteristics of the meridional velocity field at intermediate depth can be interpreted as 

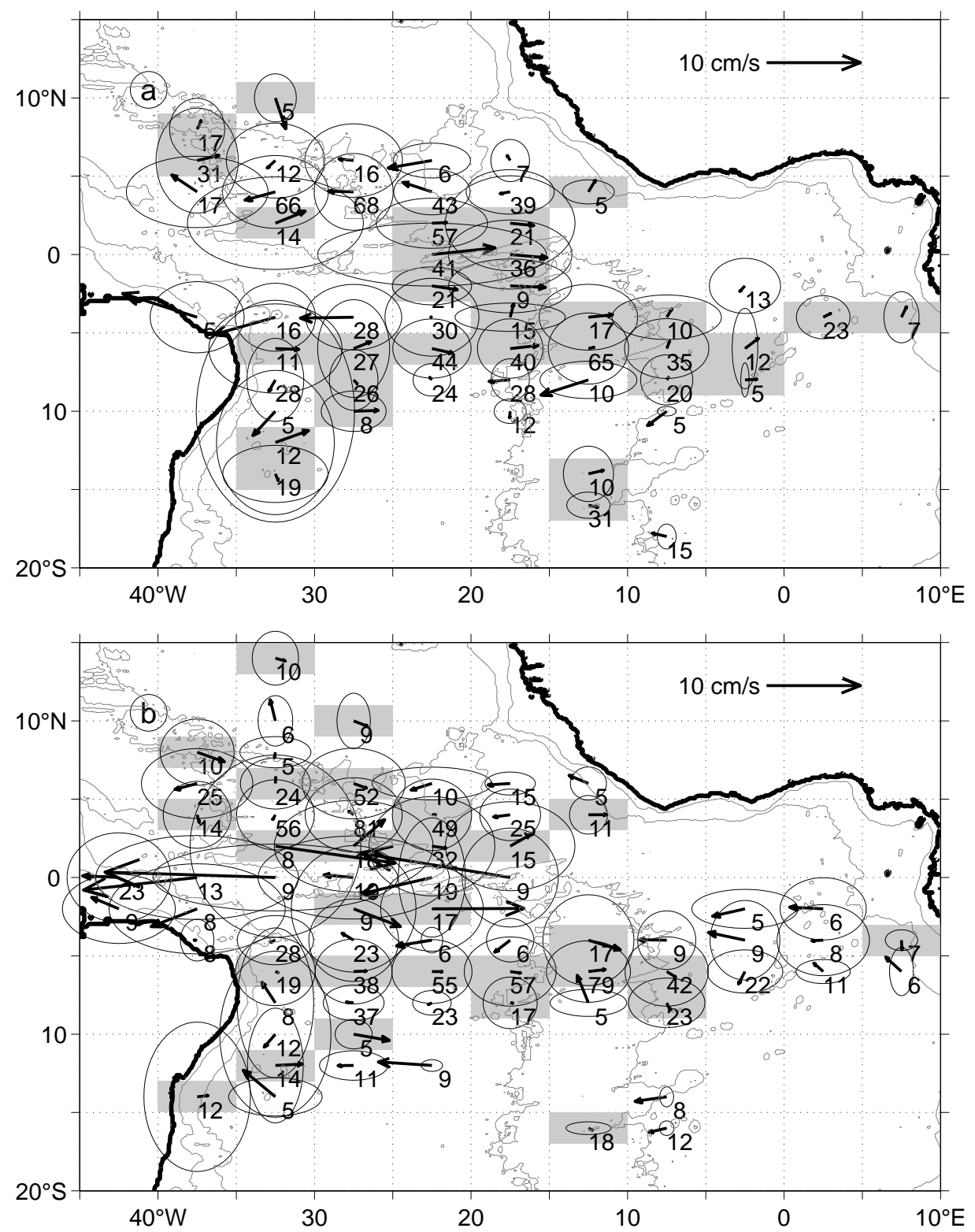

Figure 9. Mean velocities and standard deviations in $5^{\circ}$ (longitude) by $2^{\circ}$ (latitude) boxes at intermediate depth are shown for two time periods: (a) January through June; (b) July through December. The estimates are based on the displacements of the profiling floats that took place between $800 \mathrm{dbar}$ and $1100 \mathrm{dbar}$ as they are shown in Figure 2. The numbers to the lower right of the vectors indicate the number of observations in the boxes. Only boxes with at least five observations are shown. Shaded boxes indicate eastward flow. The isobaths are 1000 and $4000 \mathrm{~m}$.

an indication for the presence of a meandering current. Similar (and clearer) signs were also found in trajectories from RAFOS floats [Boebel et al., 1999a] and SOFAR floats [ Richardson and Schmitz, 1993; Richardson and Fratantoni, 1999].

The relative importance of the surface drift and the submerged drift varies widely. 
In a few cases most of the meridional displacement of a float can be attributed to its surface drift. The most prominent examples for this are floats 6 and 19 (Figure 7). In other cases the meridional drifts at the two levels are in opposite directions, which is another reason, for these floats, to stay close to $6^{\circ} \mathrm{S}$ (e.g. floats 7 and 16).

Secondly, with the exception of two floats (Figure 2 and Figures. 10a and i), the trajectories of floats deployed between $10^{\circ} \mathrm{S}$ and $10^{\circ} \mathrm{N}$ are confined to this latitude range. (This is unlikely to be caused by the drift at the surface, since the mean Ekman transport has a poleward component on both sides of the equator.) The trajectory in Figure $10 \mathrm{a}$ indicates that water parcels can leave the $10^{\circ} \mathrm{S}-10^{\circ} \mathrm{N}$ tropical band rather rapidly along the boundary. The trajectory in Figure $10 \mathrm{i}$ crosses $10^{\circ} \mathrm{N}$ in the interior, near $35^{\circ} \mathrm{W}$. Other trajectories in the interior tropics also show considerable meridional motions (Figure 8). The meridional drifts carry the floats from one zonal current to the next. In the four examples this is largely due to northward submerged drifts (more details on these transitions are given by Molinari et al., 1999; Schmid et al., 2001). However, this does not necessarily mean that a water parcel would experience such a drift. A float can, for example, be ejected from a meandering current when it goes to the surface close to the northernmost extent of a meander. If it goes back down at a time when the current has meandered far enough south it may get caught in an opposing current. As mentioned above, earlier observations [Boebel et al., 1999a; Richardson and Fratantoni, 1999] and the small mean meridional velocities with large standard deviations (Figure 9) support the meandering of the tropical currents.

\subsection{Western boundary pathways}

A northward western boundary current exists throughout the domain shown in Figure 1. Stramma and Schott [1999] indicate that the North Brazil Undercurrent is fed south of the equator by a branch of the South Equatorial Current that first turns south at about $7^{\circ} \mathrm{S}, 30^{\circ} \mathrm{W}$ and then joins the boundary south of $10^{\circ} \mathrm{S}$ (Figure 1 , top). Surveys taken at $10^{\circ} \mathrm{S}$ and $5^{\circ} \mathrm{S}$ in four different years (in 1990 to 1996) show the North Brazil Undercurrent as a current with the velocity maximum between 100 and $400 \mathrm{~m}$, and a vertical extent from the surface to at least $1000 \mathrm{~m}$ [Schott et al., 1998]. At several latitudes portions of the water in the western boundary current feed into the zonal currents, primarily the SICC and NICC (Figure 1, top). The western boundary current is, in turn, fed by a westward equatorial flow. These connections were inferred from transport estimates, which often do not yield a more precise identification of the actual pathways.

Individual trajectories can provide a more detailed perspective about the pathways connecting the zonal currents with the western boundary current than sections or box averaged data. Here, as in the discussion above, one must keep in mind that the trajectories are not continuous. Nine floats deployed on and south of the equator reached the western boundary regime (Figure 10), even though three of them experienced initial periods of eastward flow (Figures. 10a-c, see above). Five of the floats went westward (at different times) between $4^{\circ} \mathrm{S}$ and $9^{\circ} \mathrm{S}$ (Figures. 10ac, g and $h$ ), whereas the others drifted along the equator (Figures. 10d-f and i). Most of these floats continued northward once they reached the western boundary. Only 

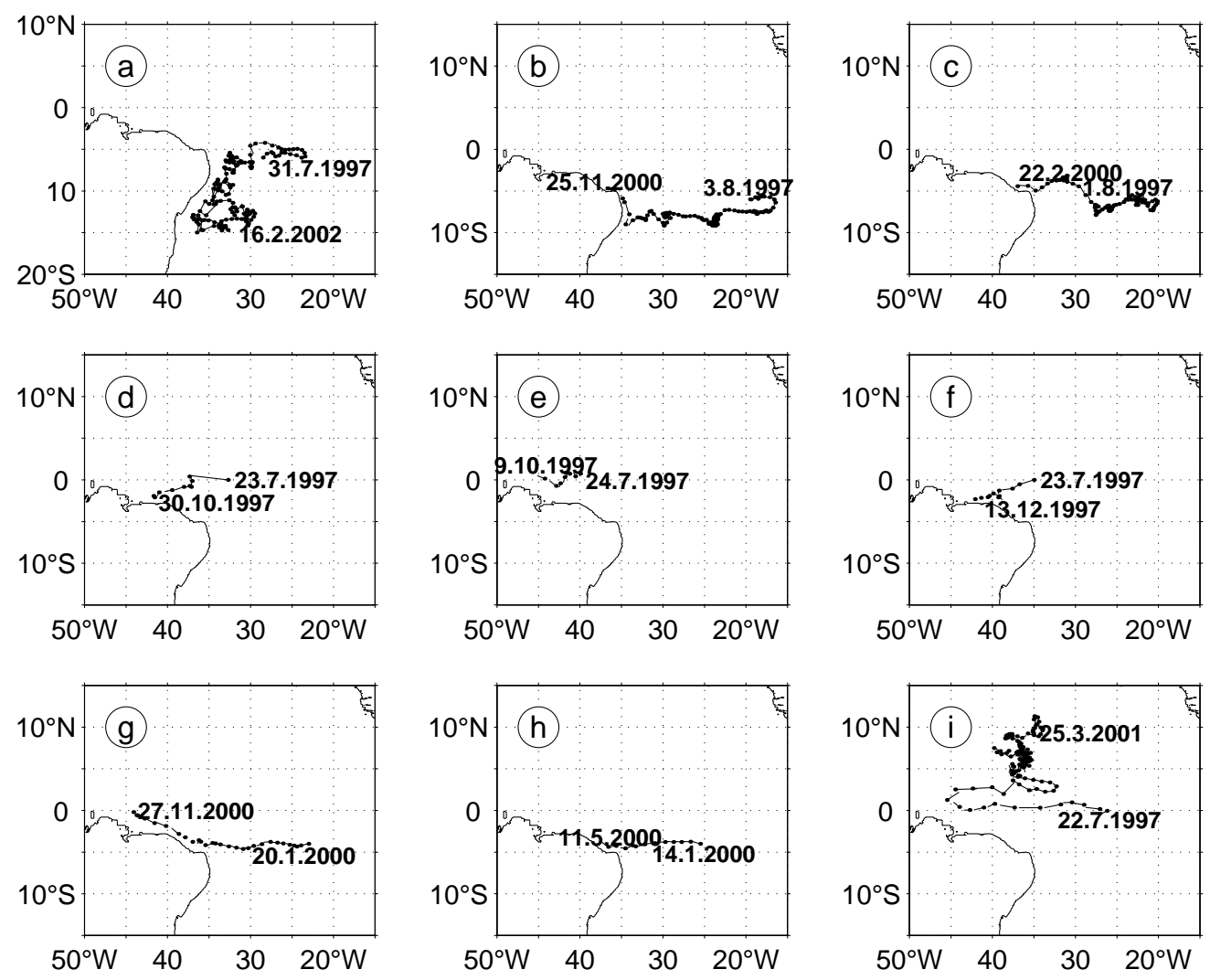

Figure 10. Examples for profiling floats that reach the western boundary. The start and end dates are given.

the float in Figure 10a experienced southward drift, probably in an eddy (Boebel et al., 1999a, observed the southward propagation of an eddy along the western boundary in this region in RAFOS trajectories). As the eddy-like drift terminated the float turned eastward, came back to the west and then turned southward once again. Throughout this period the float never came close enough to the western boundary to become entrained in the North Brazil Undercurrent, i.e. it did not follow the path suggested by Stramma and Schott [1999] and others. In contrast to this, the float in Figure 10b does reach the western boundary at a latitude consistent with the schematic and is entrained into the North Brazil Undercurrent. Two factors may be critical for the absence of that pathway in Figure 10a: (1) The large mesoscale variability of the flow during the period of observation may have effectively cut off a link that might exist at other times, and (2) The vertical extent of the North Brazil Undercurrent, and the westward current feeding into it, may have been too small to capture the float.

Seven of the eight floats that became entrained into the western boundary current ran aground. The groundings are related to the time the floats spend on the surface. During these periods the floats can be carried into shallow regions by onshore surface currents driven by the trade winds in the region. One float managed 
to stay in the boundary current, without grounding, from $5^{\circ} \mathrm{S}$ to the equator (Figure $10 \mathrm{~g}$ ). Another float entered the boundary current at the equator and left it again to be entrained into the NICC (Figure 10i). While these data are insufficient to trace a continuous flow along the boundary between $20^{\circ} \mathrm{S}$ and $15^{\circ} \mathrm{N}$ as given in Stramma and Schott (1999, their Figure 6), a pathway that is also observed in other Lagrangian observations (MARVOR, Ollitrault et al., 1995), they do provide direct observations of cross-equatorial flow and water exchanges between the boundary regime and the interior tropical Atlantic.

None of the equatorial floats (Figures. 8 and 10) followed the interior pathway, just off-shore of the boundary current, from the equator to the SICC (Figure 1, top). More observations will be needed to determine if this pathway presented by Stramma and Schott [1999] exists. In support of their schematic, a float launched on the equator (Figure 10i) joined the western boundary current (or, more precisely, was entrained into its offshore side) for a short period of time and became entrained in the NICC. Such a pathway was also indicated in the salinity maps of Suga and Talley [1995].

\subsection{Semi-annual means of the velocity at intermediate depth}

As mentioned in the introduction, there are strong signs that the intermediate depth flow along the equator varies on an annual time scale [e.g. Schott et al., 1998; Boebel et al., 1999a; Gouriou et al., 1999; Molinari et al., 1999; Richardson and Fratantoni, 1999; Schmid et al., 2001]. Essentially the equatorial flow is predominantly eastward (westward) in the first (second) half of the year. Therefore the periods January through June and July to December were chosen to estimate the mean velocities on a regular grid.

The analysis of the vertical scales gives us confidence that the 800-1100 $\mathrm{m}$ layer is likely to be mostly governed by the same flow pattern (with occasional exceptions on the equator). Submerged trajectories in this layer were binned onto a $2^{\circ}$ latitude by $5^{\circ}$ longitude grid for the two six-month time periods. This horizontal resolution is sufficient to resolve the horizontal scales derived above. The resulting velocity fields are given in Figure 9.

During the January to June time-frame (Figure 9a) the equatorial flow is to the east in contrast to the intense westward flow encountered in the second half of the year (Figure 9b), which is consistent with earlier observations [e.g. Schott et al., 1998; Boebel et al., 1999a; Molinari et al., 1999; Richardson and Fratantoni, 1999; Schmid et al., 2001]. The NICC and SICC are flowing eastward in both periods, and the flow patterns south of the SICC are very similar. In January to June (Figure 9a) the westward current at $4^{\circ} \mathrm{N}$ appears more developed than during the second half of the year (Figure 9b). In the latter period the flow north of the NICC is weak, with indications for a preference of westward flow at $4^{\circ} \mathrm{N}$ and $6^{\circ} \mathrm{N}$, supporting the existence of the westward current shown in Figure 1 (top). These similarities and the difference on the equator, for the two time periods, are also reflected in Figure 11.

In contrast to the basin-wide (semi-annual) reversal of the equatorial flow the off-equatorial flow seems to experience no basin-wide reversals, at least not in the semi-annual means (Figure 9). However, two factors indicate that a closer look 

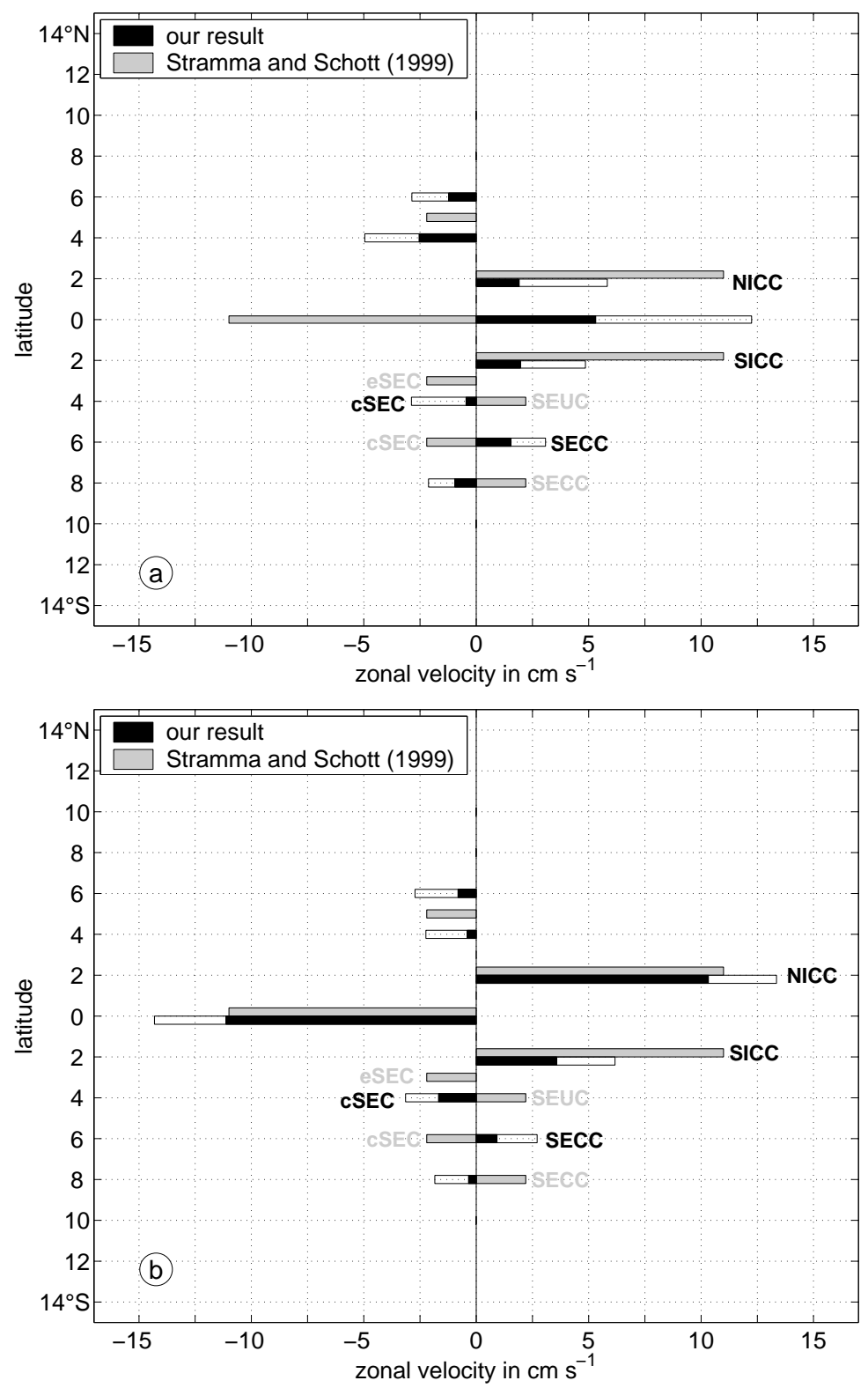

Figure 11. Zonal means and standard deviations of the zonal velocity derived from the boxaveraged velocities shown in Figure 9. No boxes near the boundary were used herein. For comparison the flow directions and approximate magnitudes (strong/weak) from Stramma and Schott (1999) are indicated. a) January through June. b) July through December. The abbreviations are: NICC $=$ Northern Intermediate Countercurrent, SICC $=$ Southern Intermediate Countercurrent, eSEC = equatorial South Equatorial Current, SEUC = South Equatorial Undercurrent, cSEC = central South Equatorial Current, SECC = South Equatorial Countercurrent.

at the off-equatorial variability is appropriate. The first factor is that the ratio of the standard deviation to the mean of the zonal velocity outside of a $6^{\circ}$ wide band around the equator is mostly larger than it is equatorward of $3^{\circ}$. In the 
off-equatorial band the ratio exceeds three in $54 \%$ of the boxes with at least five observations, whereas in the equatorial band this occurs in only $21 \%$ of the qualifying boxes. This difference is especially pronounced in July-December. Naturally, this result does not reveal any information about possible time scales of the offequatorial variability. Therefore, it is premature to decide if these currents experience seasonal reversals with a phase shift of several months with respect to the equatorial reversals, or if the different ratios are due to higher-frequency oscillations. The second factor is that certain off-equatorial boxes (Figure 9) have eastward flow in the first half of the year and westward flow in the second half of the year, or vice versa. However, it is difficult to come to a final conclusion based on these means because of data sparsity. For example, it cannot be distinguished here if this variability is due to seasonal current reversals, due to the meandering of the currents (mesoscale waves), or due to higher frequency variability.

One float, in particular, supports the idea of reversing zonal flow directions. For this float the reversal occurs without a significant change in its latitude, indicating an actual reversal of the flow (Figure 10c). For two more floats the changes of the zonal flow direction are associated with meridional displacements of the floats (Figure 10a-b). All three examples may be caused by waves with mesoscale to annual periods. Likely candidates are planetary waves which have already been associated with current reversals in the equatorial band [e.g. Molinari et al., 1999]. Contrary to the considerable total submerged meridional displacement of the $6^{\circ} \mathrm{S}$ floats (Figure 7) the box-averaged data (Figure 9) yield mostly insignificant mean meridional velocities. Therefore meridional displacements of water parcels can be seen as temporal events, which supports the wave hypothesis.

The evidence presented here can be interpreted as a sign of temporal variability in the off-equatorial currents for which the time of reversals of the zonal velocity depends on the longitude and latitude, i.e. the phase of the annual cycle depends on the geographic location. It seems likely that such variability can be caused by waves. This variability, which may have significant impact on the spreading of the water at intermediate depth, will be studied in more detail in the next section.

\section{TEMPORAL AND SPATIAL VARIABILITY BETWEEN $5^{\circ} \mathrm{S}$ AND $7^{\circ} \mathrm{S}$}

\subsection{Observations}

Figure 12a shows the velocity vectors measured by the profiling floats between 5 and $7^{\circ} \mathrm{S}$ as a function of longitude and time. This latitude band was chosen because it provides a sufficient data coverage in time and space to study the variability on the basis of a multi-year time series. Four aspects of the flow field are visible: (1) At a given time the zonal and meridional flow directions often depend on the longitude; (2) At a given longitude the zonal and meridional flow direction change over time; (3) Eastward drifts (gray) occur more often than westward drifts (black). This observation is supported by the seasonal box averages depicted in Figure 9; and (4) There are indications for westward propagating velocity signals.

Three examples for westward propagation are indicated by dashed lines in Figure 12a. They are identified by equal zonal flow directions. Each of them is based 
on data from two or more floats. The southwestward flow found near $3^{\circ} \mathrm{W}$ in the second half of 1997 appears to have propagated to $15^{\circ} \mathrm{W}$ in slightly more than half a year. Similar propagations of flow patterns are observed in 1999 from 8 to $19^{\circ} \mathrm{W}$ (westward flow) and between mid 2000 and mid 2001 from 6 to $22^{\circ} \mathrm{W}$ (eastward flow). The slopes of the dashed lines correspond to propagation velocities of 5 to $7 \mathrm{~cm} \mathrm{~s}^{-1}$.

\subsection{Comparison with MICOM}

The monthly mean MICOM velocities for layer 10, which is centered between $800 \mathrm{~m}$ and $900 \mathrm{~m}$, are shown in Figure 12b. They reveal a general pattern that is consistent with the observed flow: (1) The zonal and the meridional flow direction depend on the longitude and the time; (2) Eastward flow (gray) occurs more often (in 56\% of the model fields over the two years) than westward flow (black); and (3) Westward propagating signals are present.

In general agreement with the observations the overall mean zonal velocity derived for the two model years is eastward $\left(0.3 \pm 1.5 \mathrm{~cm} \mathrm{~s}^{-1}\right)$. The temporal mean at each grid point indicates a longitudinal dependence of the zonal flow direction in the model. West of $5^{\circ} \mathrm{W}$ the mean flow is eastward at about $0.4 \mathrm{~cm} \mathrm{~s}^{-1}$, whereas a mean westward flow of less than $0.1 \mathrm{~cm} \mathrm{~s}^{-1}$ is derived for the region east of $5^{\circ} \mathrm{W}$. The standard deviation is about $1.5 \mathrm{~cm} \mathrm{~s}^{-1}$ for both regions.

The observations (Figure $9 \mathrm{~b}$ ) support the change of direction near $5^{\circ} \mathrm{W}$. However, it must be cautioned that few observations are available east of $5^{\circ} \mathrm{W}$. One difference between the temporal variability in the model and observations needs to be mentioned here: In the model the preference of the zonal flow direction changes over time. Based on the monthly means shown in Figure 12b two seasons with significant differences of the direction of the zonal flow within the shown longitude range can be identified. From August to March eastward velocities are dominating (67\%), whereas from April to July westward velocities are more frequent (70\%). The currently available observations do not support such a change of the direction of the mean flow. More observations are necessary to determine if this difference is due to a sampling problem.

A comparison of the propagating signals yields the following: A derivation of the mean propagation velocity over the shown longitude range from the model output yields about $15 \mathrm{~cm} \mathrm{~s}^{-1}$ (as before the signals are identified by equal zonal flow directions). This velocity is more than twice as large as the velocity derived from the observations ( 5 to $7 \mathrm{~cm} \mathrm{~s}^{-1}$ ). A partial explanation for this is that, in the observations, all of the signals were found east of $20^{\circ} \mathrm{W}$. A closer look at the model reveals that the propagation velocity depends on the longitude. East of about $10^{\circ} \mathrm{W}$ the signal in the model is propagating at a similar speed as in the observations. Towards the west the propagation velocity increases.

The currently available float observations are too sparse to verify if the variability in the model velocities fully reflects the actual situation. Nevertheless, it can be concluded that the model delivers a realistic reproduction of the major features observed here. Therefore the model output is suitable to investigate the characteristics of the oscillations. 

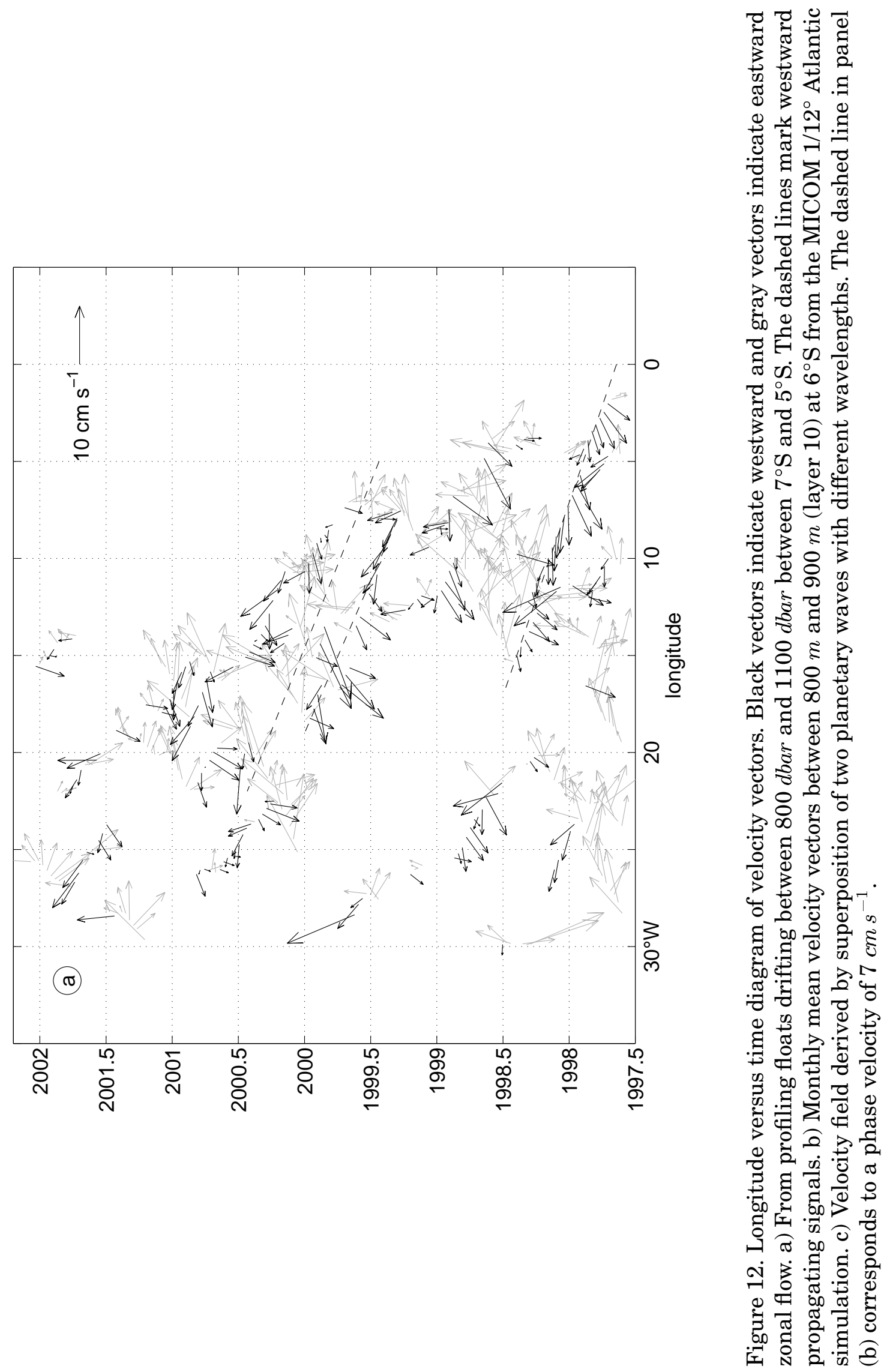


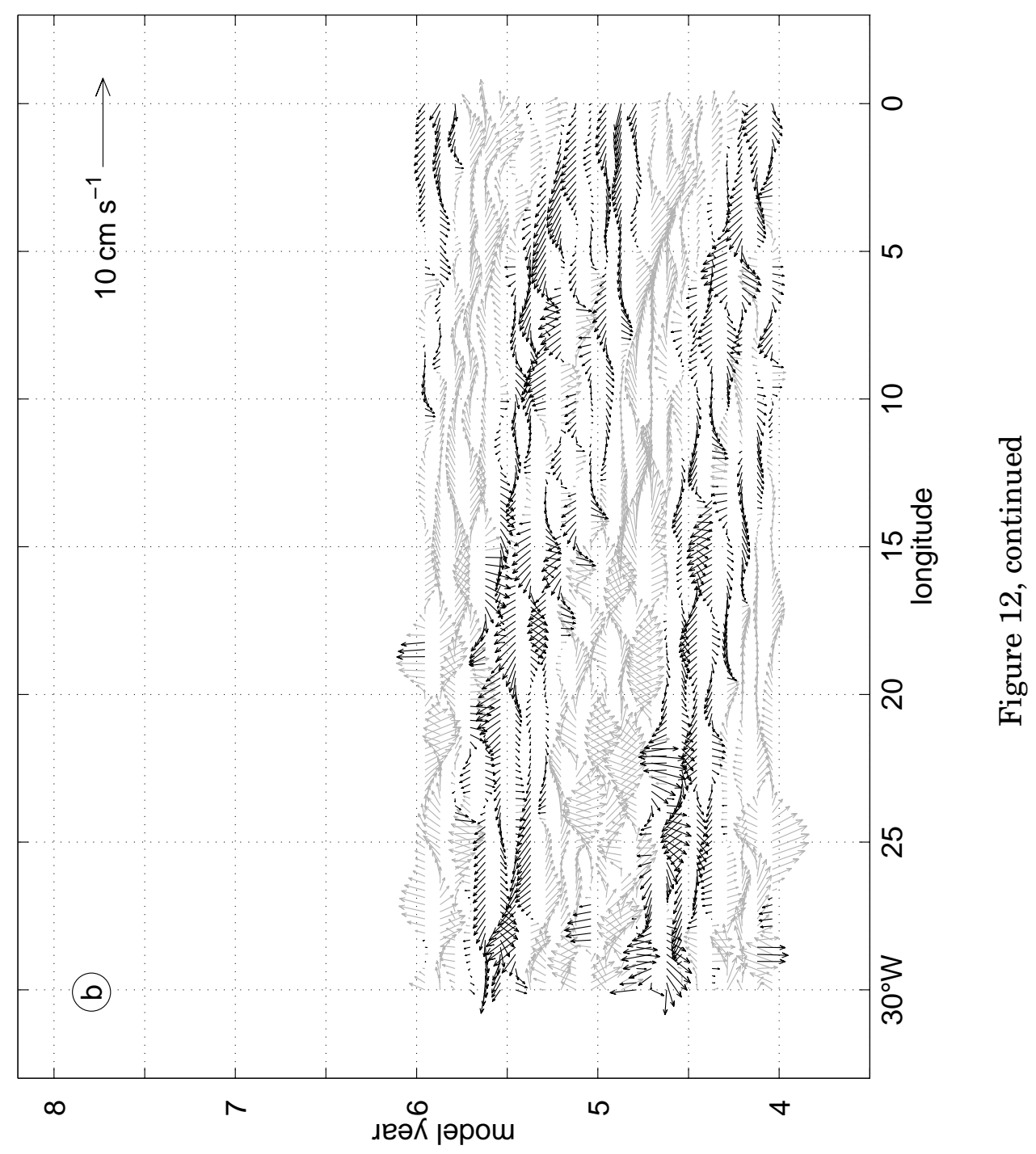




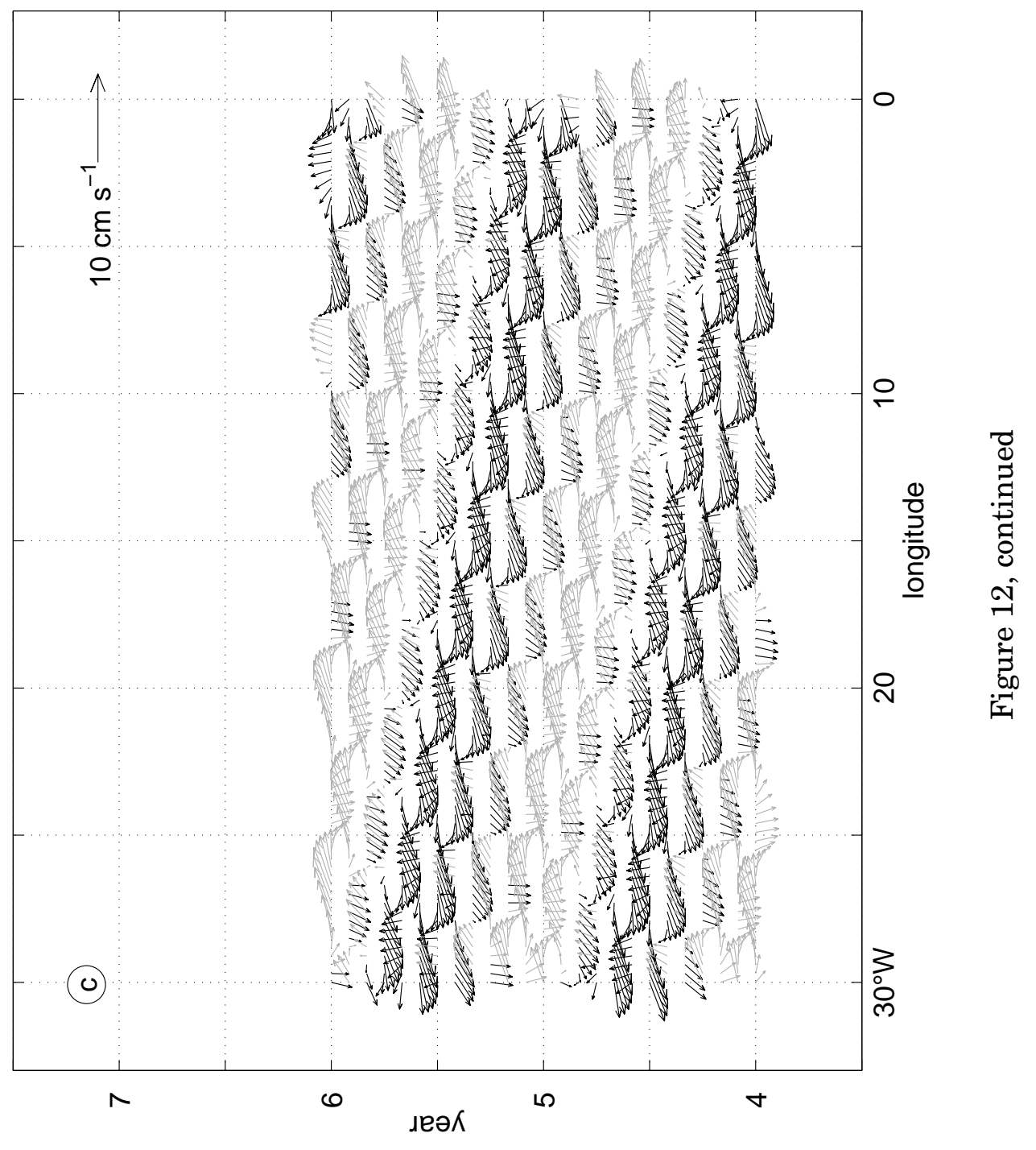


In the following the dominant time and zonal length scales will be derived from the observations and the model. Due to insufficient data coverage a spectral analysis (in time and space) of the observed velocities is not possible. Therefore, in addition to a more qualitative approach based on an interpretation of time series plots, an attempt will be made to derive the time and length scales from an analysis of the model output.

\subsection{Characteristic length scales}

Two zonal length scales can be identified in Figure 12a. One is evident as a broad region of eastward flow, which covers about $2000 \mathrm{~km}$ (between 10 and $30^{\circ} \mathrm{W}$ ) in the third quarter of 1997. The other, smaller, scale of $600-700 \mathrm{~km}$ is visible near the end of 1999 (westward flow at 8 and $14^{\circ} \mathrm{W}$ with eastward flow in between). In the model the existence of a short and a long zonal scale is even more obvious (Figure 12b). Broad regions (often exceeding $22^{\circ}$ in the longitude space) of predominantly eastor westward flow are superimposed on smaller scale variabilities with zonal scales of 2 to $5^{\circ}$. The $22^{\circ}$ for the longer scale corresponds to nearly $2500 \mathrm{~km}$.

The raw spectrum of the model velocities along $6^{\circ} \mathrm{S}$ was derived to analyze the zonal wave lengths. Figure 13 shows four examples obtained at different days of model year 4 . The analysis typically yields high energy densities at zonal wave lengths between 300 and $1100 \mathrm{~km}$. The highest energy densities mostly occur at wave lengths of 500 to $700 \mathrm{~km}$ (Figure 13a, d), and occasionally at $800 \mathrm{~km}$ (Figure 13c) or near $1100 \mathrm{~km}$ (Figure 13b). In the latter case the energy densities at 600 and $700 \mathrm{~km}$ are nearly as large as near $1100 \mathrm{~km}$. From the above it can be concluded that wave lengths in the range of 500 to $700 \mathrm{~km}$ are important in the region under consideration.

The longer zonal scale of about $2500 \mathrm{~km}$ derived from the Hofmüller diagram of the model velocity (Figure 12b, see above) might be due to a wave with a zonal wave length of about $5000 \mathrm{~km}$. It is obvious that a derivation of such a large wave length is not possible with the spectral analysis since the cut-off wave length of the spectrum is $3000 \mathrm{~km}$. (The cut-off wave length could be increased by taking the whole basin into account. The exclusion of the boundary regions was motivated by the desire to eliminate boundary influences on the spectrum.) Additionally, the information contained in high spectral energies above a wave length of $1000 \mathrm{~km}$ is very limited due to the limitation of the wave number resolution in the spectral analysis $\left(3 \cdot 10^{-4} m^{-1}\right)$.

\subsection{Characteristic time scales}

Figure 14 shows the zonal velocity from the $5^{\circ}$ longitude by $2^{\circ}$ latitude box centered at $12.5^{\circ} \mathrm{W}, 6^{\circ} \mathrm{S}$ from the observations (monthly means, black) and MICOM (one realization every 3 days, gray). Model year 4 is shown in 1998 and model year 5 in 1999.

The observations reveal a seasonal cycle, which consists of predominantly eastward zonal flow in the second half of the year and weaker alternating flow in the first half of the year. In addition there are several signs of interannual variability: (1) The eastward velocity in 1998 reaches a higher level (about $2 \mathrm{~cm} \mathrm{~s}^{-1}$ more) for a longer period than in 1999; (2) The westward zonal velocities in the first half 

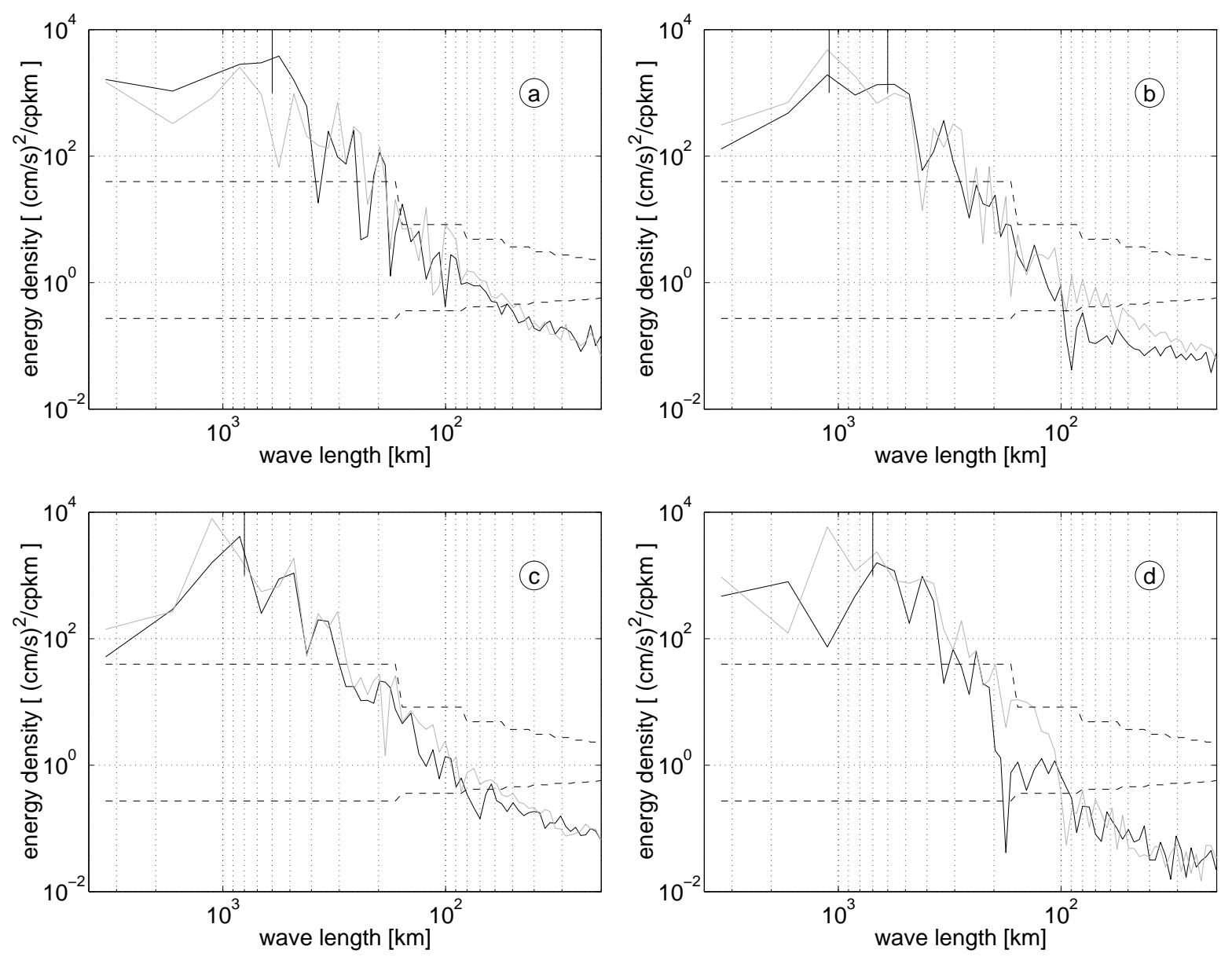

Figure 13. Examples for wave spectra at $6^{\circ} \mathrm{S}$ from MICOM model year 4 . Black and gray indicate the zonal and meridional components, respectively. The dashed lines depict the 95\% confidence limit. The method for the estimation of the confidence limits is given in section 2. (a) day 0 , the vertical line at the top marks $600 \mathrm{~km}$. (b) day 54, the vertical lines at the top mark 600 and $1100 \mathrm{~km}$. (c) day 63, the vertical line at the top marks $800 \mathrm{~km}$. (d) day 105, the vertical line at the top marks $700 \mathrm{~km}$.

of 2000 are larger than those observed in the first half of the years 1998 (by more than $2 \mathrm{~cm} \mathrm{~s}^{-1}$ ) and 1999; and (3) The beginning and the end of the period of eastward flow depends on the year. The onset of eastward flow in 1998 occurs three months earlier than in 1999 (May versus August). The termination of eastward flow is observed in December for the 1997 season, in November for the 1998 season and in March 2000 for the 1999 season. Even though the amount of data is sparse the observations suggest that oscillations occur on mesoscale, seasonal and interannual time scales.

MICOM reproduces the observed seasonal cycle and the alternating flow in the first half of the year (Figure 14, gray). As in the observations the amplitude of the variability is about $10 \mathrm{~cm} \mathrm{~s}^{-1}$, and the flow is predominantly eastward in the second half of the year. The transition from the weaker alternating flow to the 


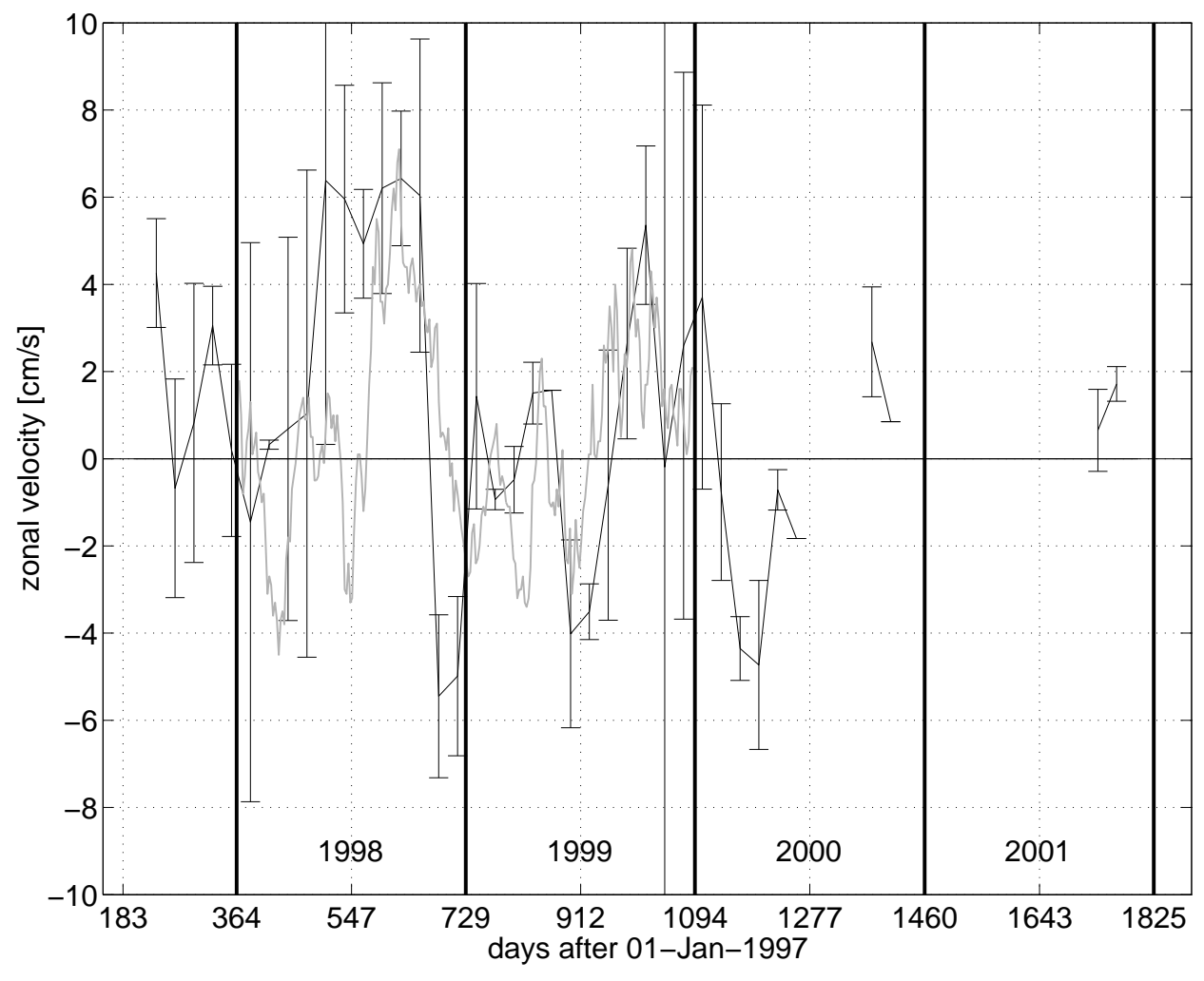

Figure 14 . Time series of the zonal velocity in the region $15^{\circ} \mathrm{W}$ to $10^{\circ} \mathrm{W}, 7^{\circ} \mathrm{S}$ to $5^{\circ} \mathrm{S}$. Positive values correspond to eastward velocities. Black: profiling float data (monthly means). Gray: MICOM (at $12.5^{\circ} \mathrm{W}, 6^{\circ} \mathrm{S}$, every three days). Model year 4 is shown in 1998 and model year 5 is shown in 1999.

predominantly eastward flow occurs in June in both model years. The time series also shows signs of an interannual variability, but the differences between the two model years are smaller than the observed differences between 1998 and 1999 . Especially the phase shifts in the model time series are quite small. This is to be expected since the model is forced with monthly climatological surface fluxes. The small changes in amplitude may be due to nonlinear effects, or they may be attributed to the possibility that the model did not reach a complete equilibrium yet. The similarities between the model and the observations show that the model output can be valuable in the identification of the characteristic time scales of the flow.

The raw spectrum of the zonal velocity from the two year long MICOM time series reveals significant peaks at mesoscale periods centered at 36, 45, 66 and 80 days (Figure 15). There are also two more peaks at the semi-annual and the annual period. Several of the peaks of the spectrum for the zonal velocity are also found in the spectrum of the meridional velocity. Differences between the two spectra are that, in the spectrum of the meridional velocity, no peak is found at 80 days, and also that significant peaks are found at 90 and 120 days. Of particular interest are the peaks at 45 days, 66 days and one year because they are very similar for the two velocity components. 


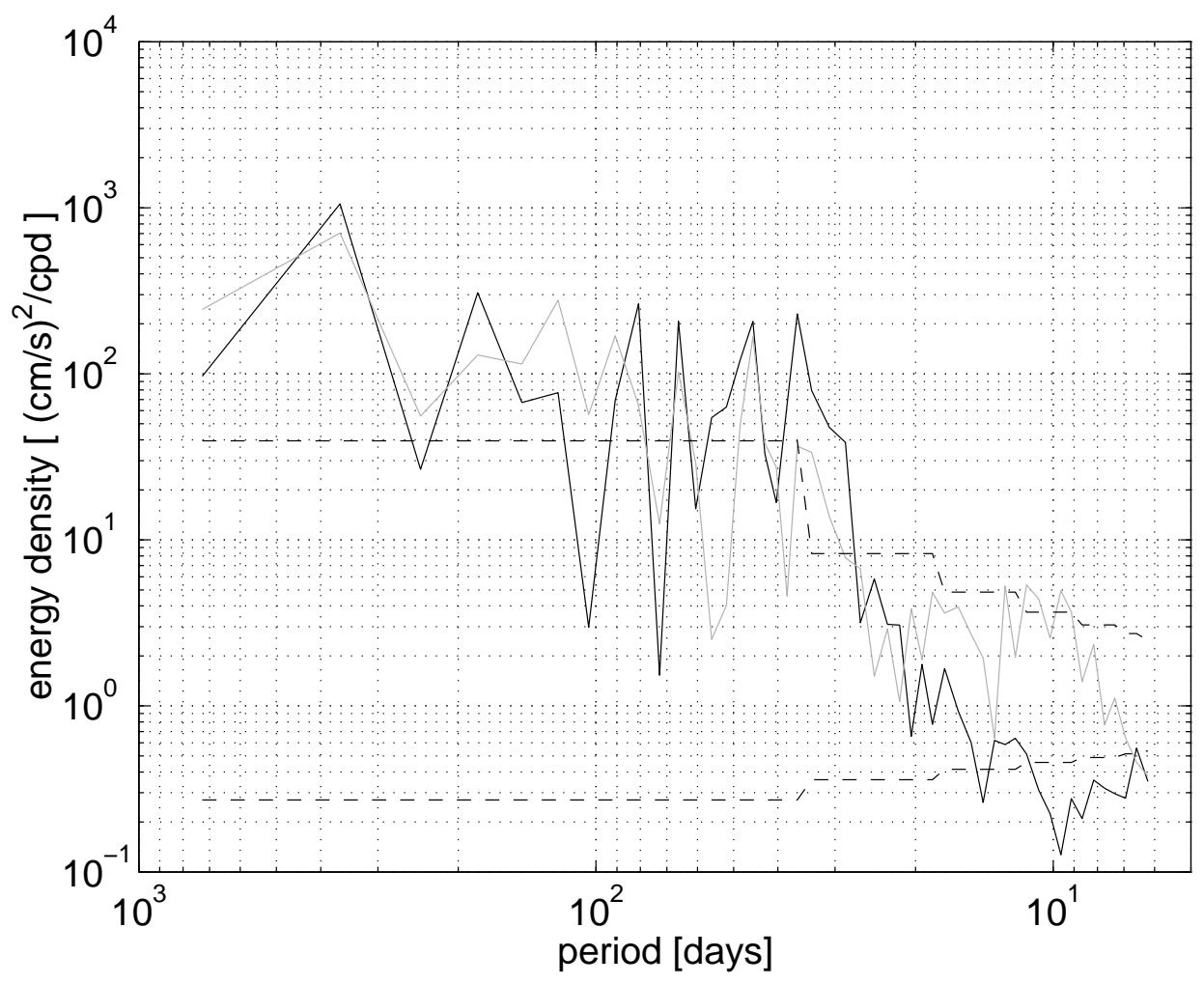

Figure 15. Spectrum of the zonal (black) and meridional (gray) velocity at about $800 \mathrm{~m}$ from two years of MICOM data at $6^{\circ} \mathrm{S}, 12.5^{\circ} \mathrm{W}$ (at the geographic location used for Figure 14). The dashed lines depict the $95 \%$ confidence limit. The method for the estimation of the confidence limits is given in section 2 .

\subsection{Kinematic analysis}

It was shown above that the observations and MICOM results indicate the existence of two dominant zonal wave lengths. The shorter wave length is frequently within 500-700 km, and the longer wave length appears to be about $5000 \mathrm{~km}$. The dominant periods of the variability for both velocity components in MICOM are 45 days, 66 days and one year. It seems likely that the variability is due to planetary waves, for which the mesoscale periods correspond to the shorter waves and the annual period corresponds to the longer wave. At the period of 45 days the energy densities for the velocity components deviate more strongly from each other than at the other two periods. Therefore the primary focus in this section will be on the annual and the 66 day period.

Based on the above a flow field will be derived from the analytical planetary wave solution of the equations of motion, and it will be compared to the MICOM output. The first order velocity field of planetary waves is the geostrophic velocity given by the equations $u=l g \eta / f \sin (k x+l y-\omega t)$ and $v=-k g \eta / f \sin (k x+l y-\omega t)$, for the zonal and meridional component, respectively [Gill, 1982]. Here $x$ and $y$ are the zonal and meridional distance, $t$ is the time, $\eta$ is the surface elevation, $k$ and $l$ are the zonal and meridional wave numbers, $g$ is the gravitational acceleration, $f$ 

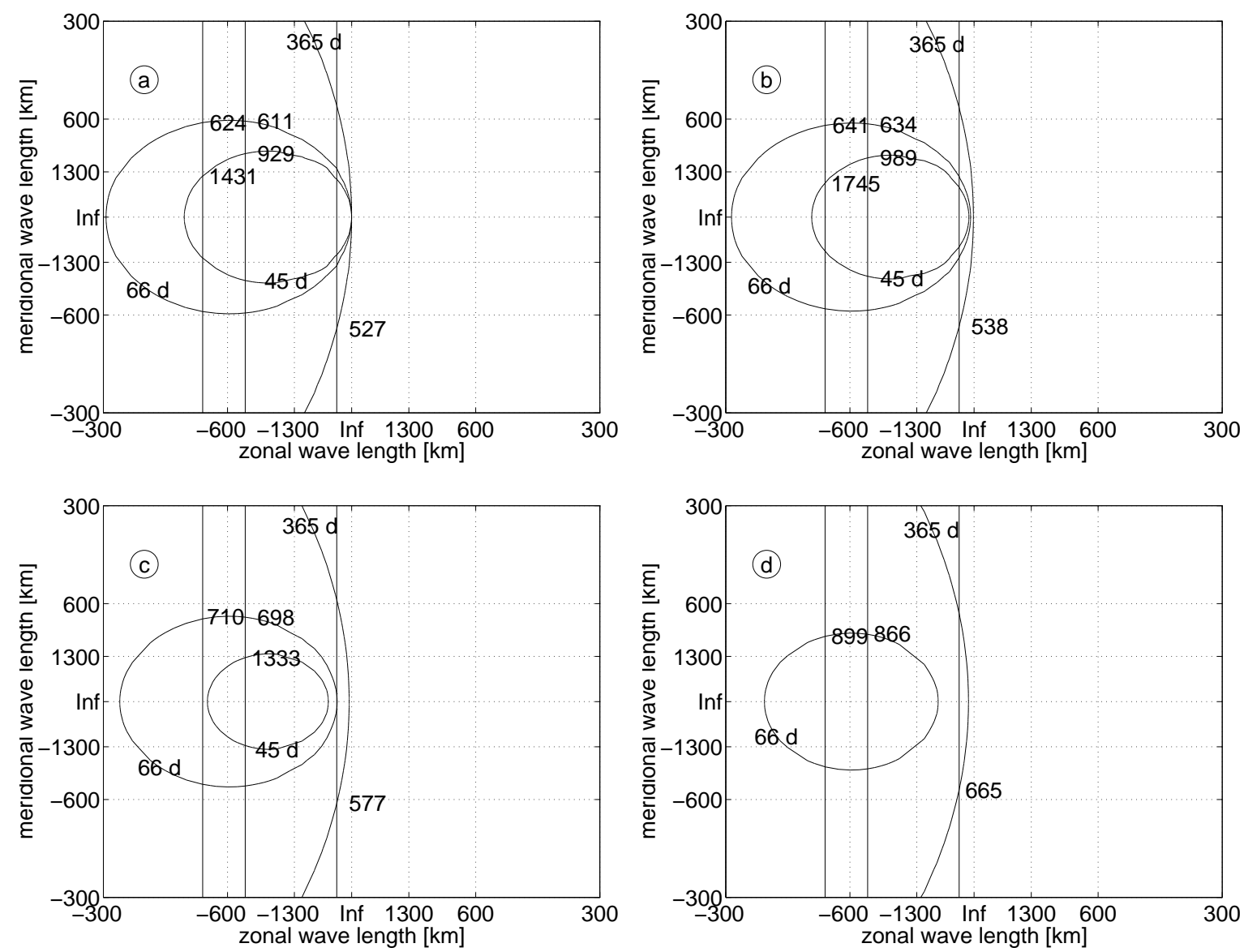

Figure 16. Dispersion relation for planetary waves at $6^{\circ} \mathrm{S}$ for the barotropic mode (a) and the first three baroclinic modes ( $b-d$, see Table 1$)$. The vertical lines indicate zonal wave lengths of 500, 700 and $5000 \mathrm{~km}$. The curved lines refer to periods found in the spectral analysis of the MICOM time series. The numbers with a 'd' give the periods, and the numbers without a unit correspond to meridional wave lengths in kilometers.

is the Coriolis parameter, $\omega$ is the angular frequency (derived from the dispersion relation for planetary waves, $\omega=-\beta k /\left(k^{2}+l^{2}+f^{2} /\left(g h_{n}\right)\right), \beta=\delta f / \delta y$, and $h_{n}=$ water depth (for barotropic mode) or equivalent depth (for baroclinic modes). The phase velocity of planetary waves can be derived from the dispersion relation as $\overrightarrow{c_{p}}=-\beta /\left(k^{2}+l^{2}+f^{2} /\left(g h_{n}\right)\right) /\left(k^{2}+l^{2}\right)\left\{k^{2}, k l\right\}$, and the group velocity is given by $\overrightarrow{c_{g}}=\beta /\left(k^{2}+l^{2}+f^{2} /\left(g h_{n}\right)\right)^{2}\left\{k^{2}-l^{2}-f^{2} /\left(g h_{n}\right), 2 k l\right\}$. The vertical modes for this study are derived using $N^{2}=2.4217 \cdot 10^{-5} s^{-2}$ in the equation for the equivalent depth $\left(h_{n}=N^{2} * H^{2} / g / \pi^{2} / n^{2}\right)$, where $n$ gives the mode number (greater than zero). In this calculation the water depth $(H)$ is set to $4000 \mathrm{~m}$. Similarly, for the barotropic mode the equivalent depth is set to $4000 \mathrm{~m}$. The application of the equations for mid-latitude planetary waves is motivated by the observation that the annual and the mesoscale waves in an animation of the MICOM velocity fields do not propagate parallel to the equator (not shown), i.e. they are not equatorially trapped waves. 
Table 1

Wave characteristics of planetary waves at $6^{\circ} \mathrm{S} . T=2 \pi / \omega$ is the period ( $\omega$ is the frequency derived from the dispersion relationship for planetary waves), $\lambda_{x}$ and $\lambda_{y}$ are the zonal and meridional wave length, $c_{p x}$ and $c_{p y}$ are the zonal and meridional phase velocity, $c_{g x}$ and $c_{g y}$ are the zonal and meridional group velocity, and $h_{n}$ is the water depth (for the barotropic mode) or the equivalent depth (for the baroclinic modes).

\begin{tabular}{|c|c|c|c|c|c|c|}
\hline $\begin{array}{r}T \\
\text { days }\end{array}$ & $\begin{array}{r}\lambda_{x} \\
\mathrm{~km}\end{array}$ & $\begin{array}{r}\lambda_{y} \\
\mathrm{~km}\end{array}$ & $\begin{array}{r}c_{p x} \\
c m s^{-1}\end{array}$ & $\begin{array}{r}c_{p y} \\
c m s^{-1}\end{array}$ & $\begin{array}{r}c_{g x} \\
c m s^{-1}\end{array}$ & $\begin{array}{r}c_{g y} \\
c m s^{-1}\end{array}$ \\
\hline \multicolumn{7}{|c|}{ barotropic mode $h_{n}=4000 \mathrm{~m}$} \\
\hline 45 & -500 & 1431 & -11.5 & 4.0 & 10.1 & -8.0 \\
\hline 45 & -700 & 929 & -11.5 & 8.7 & 5.0 & -17.3 \\
\hline 66 & -500 & 624 & -5.4 & 4.3 & 1.9 & -8.6 \\
\hline 66 & -700 & 611 & -5.3 & 6.1 & -1.7 & -12.1 \\
\hline 365 & -5000 & -527 & -0.2 & -1.7 & -15.5 & 3.3 \\
\hline \multicolumn{7}{|c|}{ first baroclinic mode $h_{n}=4 m$} \\
\hline 45 & -500 & 1745 & -11.9 & 3.4 & 10.1 & -6.6 \\
\hline 45 & -700 & 989 & -12.0 & 8.5 & 4.9 & -16.2 \\
\hline 66 & -500 & 641 & -5.5 & 4.3 & 1.9 & -8.3 \\
\hline 66 & -700 & 634 & -5.6 & 6.1 & -1.6 & -11.9 \\
\hline 365 & -5000 & -538 & -0.2 & -1.7 & -15.5 & 3.2 \\
\hline \multicolumn{7}{|c|}{ second baroclinic mode $h_{n}=1 \mathrm{~m}$} \\
\hline 45 & -700 & 1333 & -14.1 & 7.4 & 5.0 & -12.1 \\
\hline 66 & -500 & 710 & -5.9 & 7.1 & 1.9 & -7.5 \\
\hline 66 & -700 & 698 & -6.1 & 6.2 & -1.6 & -10.8 \\
\hline 365 & -5000 & -577 & -0.2 & -1.8 & -15.5 & 3.0 \\
\hline \multicolumn{7}{|c|}{ third baroclinic mode $h_{n}=0.4 \mathrm{~m}$} \\
\hline 66 & -500 & 899 & -6.7 & 3.7 & 1.9 & -5.9 \\
\hline 66 & -700 & 866 & -7.4 & 6.0 & -1.6 & -8.6 \\
\hline 365 & -5000 & -665 & -0.3 & -2.1 & -15.5 & 2.6 \\
\hline
\end{tabular}


Before the velocity field can be derived from the analytical wave solution it is necessary to estimate the meridional wave lengths and the vertical modes that satisfy the characteristics described above. For this purpose the dispersion relationship will be analyzed for different vertical modes, with a focus on the periods identified in MICOM. Figure 16 shows the dispersion curves for three periods, three zonal wave lengths and four vertical modes. The corresponding meridional wave lengths can be derived from the crossover points of the curves of constant periods with the lines representing zonal wave lengths. The associated wave velocities are given in Table 1. According to the dispersion relationship, the requirement to conserve the periodicity and the zonal wave length requires that a change of the vertical mode is compensated for by a change of the meridional wave length. It is found that the wave velocities are weakly dependent of the vertical mode under the above requirements.

It needs to be noted here that the model only resolves modes 0 to 2 (not shown), whereas observations indicate that higher modes are also present (sometimes mode 3 or 4 are dominant, such higher modes can be seen in profiles obtained during the Equalant cruise in 1999, Gouriou et al., 2001). However, this will primarily lead to an underestimation of the meridional wave length for a given period, since the zonal wave length and the period are prescribed.

Based on the finding that the chosen mode has a small impact on the wave velocities the barotropic mode is used to derive the flow at $6^{\circ} \mathrm{S}$ from the planetary wave solution. For the first wave, assuming it has a 66 day period and a zonal wave length of $700 \mathrm{~km}$ the meridional wave length is $611 \mathrm{~km}$ (Table 1). The second (annual) wave with a zonal wave length of $5000 \mathrm{~km}$ has a meridional wave length of $527 \mathrm{~km}$. The surface elevation was set to $2.5 \mathrm{~cm}$ for both waves. They were chosen to yield velocities of the same magnitude as in the observations. A study by Döös [1999] showed that the amplitude of the annual cycle of the sea surface elevation in the region of interest is between 2 and $3 \mathrm{~cm}$, which is consistent with the $2.5 \mathrm{~cm}$ chosen herein.

The mean zonal propagation velocity of the annual signal in the Hoffmüller diagram of the model velocities (15 $\mathrm{cm} \mathrm{s}^{-1}$; Figure $\left.12 \mathrm{~b}\right)$ is much larger than the zonal component of the theoretical phase velocity for the annual planetary wave (-0.2 $\mathrm{cm} \mathrm{s}^{-1}$; Table 1). However, this difference does not imply an inconsistency, because the zonal propagation velocity is a projection of the phase speed vector (pointing towards the southwest, $187^{\circ}$ ) onto a zonal line.

Figure 12c shows the flow field derived by superposition of the two planetary waves. As expected, the resulting velocity field reproduces the predominant features visible in the Hoffmüller diagram of the model velocity (Figure 12b), primarily the semi-annual reversals of the zonal flow (e.g. mostly westward in the first half of the year and mostly eastward in the second half of the year at $12.5^{\circ} \mathrm{W}$ ) and the higher-frequency changes of the meridional flow. As in both the observations and the model, the reversals of the zonal flow occur at different times, depending on the longitude. The higher-frequency variability is similar to the model as well, but there are also some discrepancies. Matching patterns are the alternating northand southward flow (at any given time) and the month-to-month change of the 
meridional flow direction, which can be seen at many times and longitudes in the model (Figure $12 \mathrm{~b}$, e.g. at $5^{\circ} \mathrm{W}$ and at $25^{\circ} \mathrm{W}$ in the first half of year 4 ) and throughout in the analytical result (Figure 12c). Other cases in the model (Figure 12b) are either nearly stationary wave crests (e.g. in the second half of year 5 near $2^{\circ} \mathrm{W}$ ) or gradual westward shifts of wave crests over several months (e.g. in the second half of year 4 around $5^{\circ} \mathrm{W}$ ). In addition the amplitude of the meridional velocity signal varies. These features can not be reproduced by the simple analytical solution. The primary reasons are the existence of planetary waves with different wave lengths than those used in the analytical solution (e.g. the wave with a 45 day period), and the continued forcing which can affect existing waves and trigger new waves.

\section{DISCUSSION AND CONCLUSIONS}

Quasi-Lagrangian observations obtained with profiling floats indicate that the intermediate depth flow in the tropical Atlantic is highly variable. An analysis of the typical spatial and temporal scales, as well as the propagation of velocity signals along $6^{\circ} \mathrm{S}$ indicates that the variability found in the ocean and in the Miami Isopycnic Coordinate Ocean Model (MICOM) can be linked to planetary waves. The observed velocity signals propagate westward at 5 to $7 \mathrm{~cm} \mathrm{~s}^{-1}$ in the eastern basin. Similar signals are found in the model output. They have a mean propagation speed of about $15 \mathrm{~cm} \mathrm{~s}^{-1}$, with lower speeds in the eastern basin and higher speeds in the western basin. The speeds in the eastern basin match those in the observations.

The analysis shows that two planetary waves are sufficient to reproduce a large part of the variability. One of them has an annual period, a zonal (meridional) wave length of $5000 \mathrm{~km}(527 \mathrm{~km})$ and is propagating towards the south $\left(187^{\circ}\right)$ at a phase speed of about $1.7 \mathrm{~cm} \mathrm{~s}^{-1}$. This results in an expected mean propagation speed of $15 \mathrm{~cm} \mathrm{~s}^{-1}$ for signals observed along $6^{\circ} \mathrm{S}$. The second wave has a period of 66 days, and a zonal (meridional) wave length of $700 \mathrm{~km}(611 \mathrm{~km})$. These two waves together result in a good reproduction of the major features found in the Hoffmüller diagram of the model velocities.

On the equator Böning and Schott [1993] found that the variability with the longer period is caused by wind forcing, whereas the waves with shorter (mesoscale) periods are due to the strong shear of the currents in the upper layer. It seems likely that the annual planetary wave at $6^{\circ} \mathrm{S}$ is also forced by the variability of the wind field. For the mesoscale waves, the shear of the upper layer currents near $6^{\circ} \mathrm{S}$ is a less likely trigger for the mesoscale variability found in the observations and the model, because the shear is significantly weaker than the shear on the equator. In the model the wind field can not be a forcing mechanism for the mesoscale planetary waves, since the model forcing is based on monthly mean wind fields.

The schematic for the mean flow at intermediate depth in Figure 17 is based on a combination of the improved understanding of the variability, the semi-annual means in Figure 9, individual trajectories and the circulation pattern derived by Stramma and Schott [1999]. The latter was primarily used to fill in gaps near the eastern and western boundaries. The locations of the Southern and Northern In- 


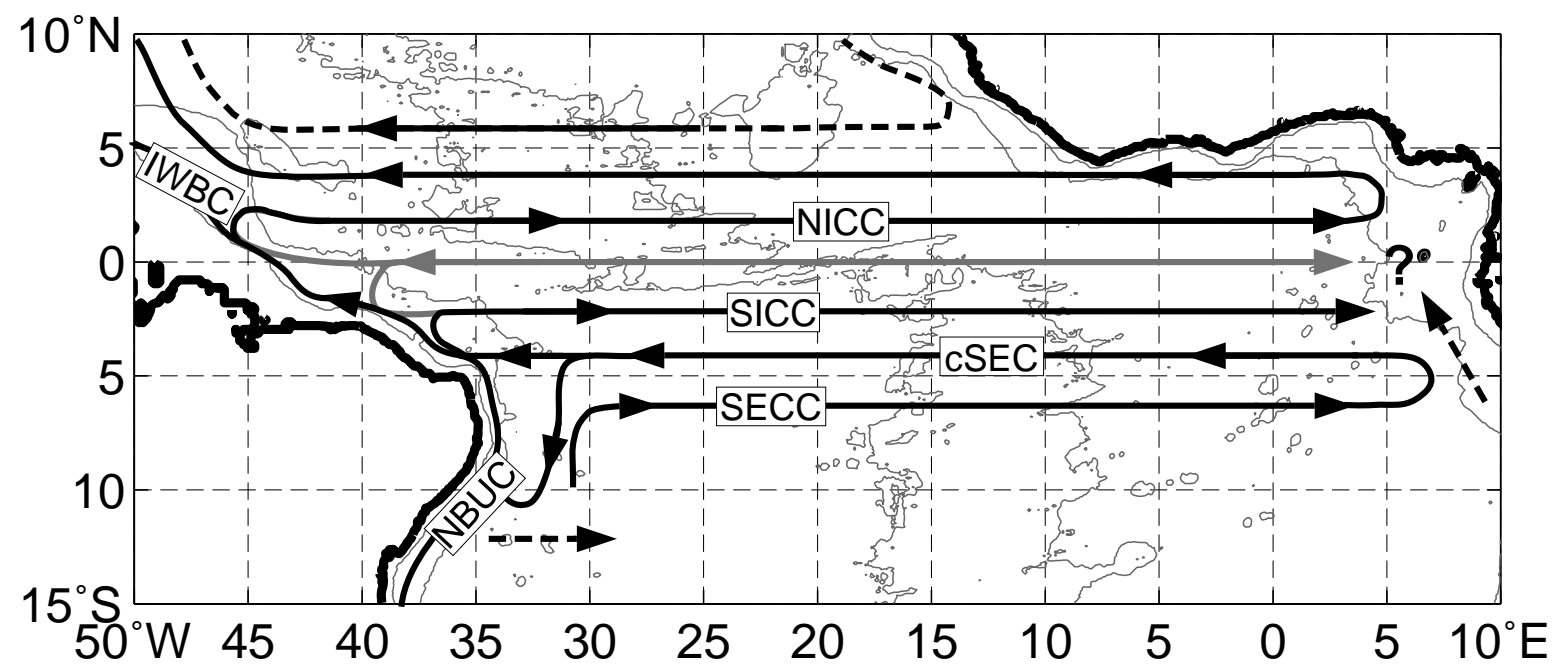

Figure 17. Schematic of mean Antarctic Intermediate Water circulation. Gray indicates seasonal changes. Dashed lines indicate uncertainty of proposed pathways. The abbreviations are: IWBC $=$ Intermediate Western Boundary Current, NBUC $=$ North Brazil Undercurrent, NICC = Northern Intermediate Countercurrent, SICC = Southern Intermediate Countercurrent, SEUC = South Equatorial Undercurrent, cSEC = central South Equatorial Current, SECC = South Equatorial Countercurrent.

termediate Countercurrent are well established in earlier and in our new data. The means from the observations indicate that the flow at $6^{\circ} \mathrm{S}$ is eastward (South Equatorial Countercurrent). The model supports this result. Similarly the observations reveal westward flow at $4^{\circ} \mathrm{S}$ (central South Equatorial Current). These positions are about $2^{\circ}$ farther north than those presented by Stramma and Schott [1999]. The South Equatorial Undercurrent is not included in Figure 17, because the new data do not support its presence at intermediate depth. The differences between the positions of the currents in the two schematics are due to two factors. One is that Stramma and Schott [1999] derived the flow for a larger depth range extends to shallower depths (500 to $1200 \mathrm{~m}$ versus 800 to $1100 \mathrm{~m}$ ). The other is that it is very difficult to derive the mean flow from synoptic sections of velocities and tracers [Molinari, 1982; Stramma, 1991; Warner and Weiss, 1992; Schott et al., 1995, 1998; Suga and Talley, 1995], and relatively sparse Lagrangian observations [Boebel et al., 1999a].

Near the western boundary our results indicate that the central South Equatorial Current is bifurcating into a westward and a southward branch (Figures. 10a, c, g and h). The direct feeding of the central South Equatorial Current into the North Brazil Undercurrent, the westward branch, is not present in the top panel of Figure 1. A possible explanation for this is the following. In a study using quasisynoptic observations from several cruises Schott et al. [1998] found that during two different seasons (fall and spring) the flow across about $32^{\circ} \mathrm{W}$ between $5^{\circ} \mathrm{S}$ and $10^{\circ} \mathrm{S}$ (the extent of the section) was eastward on the isopycnal $\sigma_{\Theta}=27.28 \mathrm{~kg} \mathrm{~m}^{-3}$. 
Since the Stramma and Schott [1999] schematic has the central South Equatorial Current at $6^{\circ} \mathrm{S}$ these observations make it impossible for the central South Equatorial Current to feed directly into the North Brazil Undercurrent. If the mean central South Equatorial Current is at $4^{\circ} \mathrm{S}$, as indicated by our new observations, a direct westward branch to the North Brazil Undercurrent can exist in consistency with the observations by Schott et al. [1998]. However, such a connection is unlikely to exist at all times. At two different times a southward deflection of floats was observed, once by [Boebel et al., 1999b], and again in Figure 10a. In both cases the southward deflection of the floats is associated with an eddy.

In the eastern basin two major differences between the schematics are apparent (Figures. 1, top and 17). One is the absence of the cyclonic gyre proposed earlier by, e.g. Warner and Weiss [1992] and Stramma and Schott [1999]. The other is the southward eastern boundary current fed by the Southern Intermediate Countercurrent which is absent in the new schematic. Instead, the semi-annual mean velocities in Figure 9 indicate that, on average, the central South Equatorial Current and the South Equatorial Countercurrent may be basin-wide currents, and that the flow at $6^{\circ} \mathrm{S}$ near the eastern boundary may be northward (our Lagrangian data only show this for the second half of 1997, when the two floats were in the region). In the presence of the proposed cyclonic gyre the flow near the eastern boundary would be southward. It remains to be seen if seasonal variabilities can cause these differences.

As already found in many earlier studies the zonal flow at intermediate depth on the equator is governed by an annual cycle [e.g. Schott et al., 1998; Boebel et al., 1999a; Molinari et al., 1999; Richardson and Fratantoni, 1999; Schmid et al., 2001]. The reversal of this flow is indicated by the gray shading of the vector in Figure 17. The reversals have a direct impact on the water exchange with the boundary currents. In the west the time-dependent connections between the equatorial flow and the boundary current are indicated in gray in Figure 17. In the east a question mark indicates the region where uncertainty is much larger. During the season of eastward flow along the equator the current may split up at the eastern boundary to feed the westward currents poleward of the Northern Intermediate Countercurrent and Southern Intermediate Countercurrent. During the season of westward flow the water coming from South Equatorial Countercurrent and spreading northward along the eastern boundary can either continue to the equator or join the westward central South Equatorial Current. The former pathway is supported by Schmid et al. [2001], who observed that, in July 1997, the minimum salinity on the equator is the same as the minimum salinity in the east at $6^{\circ} \mathrm{S}$. Additionally, the equatorial current may be fed by water from the Northern and Southern Intermediate Countercurrents.

Some trajectories indicate that the intermediate water may spread meridionally in the interior (Figures. 7 and 8). However, this may be an artifact of the regular surfacing of the floats (they are quasi-Lagrangian). In general the distribution of the meridional displacements of the floats deployed at $6^{\circ} \mathrm{S}$ (Figure 7) and the relative magnitude of the means and the standard deviations (Figure 9) show that the variability of the meridional velocity does not depend on the longitude, and 
that the mean is mostly insignificant. Occasional exceptions from the latter are probably due to insufficient data coverage.

\section{Acknowledgements}

This study was supported by National Oceanic and Atmospheric Administration (Office of Global Programs and Atlantic Oceanographic and Meteorological Laboratory). This research was carried out in part under the auspices of the Cooperative Institute for Marine and Atmospheric Studies, a joint institute of the University of Miami and the National Oceanic and Atmospheric Administration, cooperative agreement \#NA67RJ0149. Valuable data sources for this study are the NCEP Reanalysis project and the MICOM (Miami Isopycnic Coordinate Ocean Model) modelling efforts. The NCEP Reanalysis data are provided by the NOAA-CIRES Climate Diagnostics Center, Boulder, Colorado, USA. The high-resolution MICOM data were provided by Eric Chassignet (RSMAS, University Miami, Florida, USA) through Steve Worley (NCAR, Boulder, Colorado, USA).

\section{REFERENCES}

Bleck, R. and E. Chassignet, Simulating the oceanic circulation with isopycniccoordinate models. in The Oceans: Physical-Chemical Dynamics and Human Impact, S. K. Majundar, ed., 17-39, 1994.

Bleck, R., C. Rooth, D. Hu, and L. T. Smith, Salinity-driven thermocline transients in a wind- and thermohaline-forced isopycnic coordinate model of the North Atlantic. J. Phys. Oceanogr., 22, 1486-1505, 1992.

Boebel, O., C. Schmid, and W. Zenk, Flow and recirculation of Antarctic Intermediate Water across the Rio Grande Rise. J. Geophys. Res., 102(C9), 20,96720,986, 1997.

Boebel, O., C. Schmid, and W. Zenk, Kinematic elements of Antarctic Intermediate Water in the western South Atlantic. in New Views of the Atlantic, W. Zenk, R. G. Peterson, and J. R. E. Lutjeharms, eds., Deep-Sea Res. II, 46 (1-2), 355392, 1999a.

Boebel, O., R. E. Davis, M. Ollitrault, R. G. Peterson, P. L. Richardson, C. Schmid, and W. Zenk, The intermediate depth circulation of the Western South Atlantic. Geophys. Res. Lett., 26(21), 3329-3332, 1999 b.

Böning, C. and F. A. Schott, Deep currents and the eastward salinity tongue in the equatorial Atlantic: Results from an eddy-resolving, primitive equation model. J. Geophys. Res., 98(C4), 6991-6999, 1993.

Chassignet, E. P. and Z. D. Garraffo, Viscosity parameterization and the Gulf Stream separation. in From Stirring to Mixing in a Stratified Ocean. Proceedings 'Aha Huliko'a Hawaiian Winter Workshop. U. of Hawaii. January 15-19, 2001., P. Muller and D. Henderson, eds., U. of Hawaii, 37-41, 2001.

Da Silva, A. M., C. C. Young, and S. Levitus, Atlas of surface marine data 1994, Volume 1. algorithms and procedures. NOAA/NESDIS, 1994.

Döös, K., Influence of the Rossby waves on the seasonal cycle in the tropical Atlantic. J. Geophys. Res., 104(C12), 29,591-29,598, 1999. 
Fischer, J. and M. Visbeck, Deep velocity profiling with self-contained ADCPs. J. Atmos. Oceanic Technol., 10(10), 764-773, 1993.

$\mathrm{Fu}$, L.-L., The general circulation and meridional heat transport of the subtropical South Atlantic determined by inverse methods. J. Phys. Oceanogr., 11(9), 1171-1193, 1981.

Gill, A. E., Atmosphere-Ocean Dynamics. Academic Press, 1982.

Gouriou, Y., C. Andrié, B. Bourlès, S. Freudenthal, S. Arnault, A. Aman, G. Eldin, Y. du Penhoat, F. Baurand, F. Gallois, and R. Chuchla, Deep circulation in the equatorial Atlantic Ocean. Geophys. Res. Lett., 28(5), 819-822, 2001.

Gouriou, Y., B. Bourlès, H. Mercier, and R. Chuchla, Deep jets in the equatorial Atlantic Ocean. J. Geophys. Res., 104(C9), 21,217-21,226, 1999.

Hacker, P., E. Firing, W. D. Wilson, and R. L. Molinari, Direct observations of the current structure east of the Bahamas. Geophys. Res. Lett., 23(10), 11271130, 1996.

Holfort, J., Großräumige Zirkulation und meridionale Transporte im Südatlantik. $\mathrm{Ph}$. D. thesis, Christian-Albrechts-Universität, Kiel. 103 pp, 1994.

Keffer, T., The ventilation of the world's oceans: Maps of potential vorticity fields. J. Phys. Oceanogr., 15, 509-523, 1985.

Levitus, S., Climatological Atlas of the World Ocean. NOAA Prof. Paper 13, U.S. Dept. of Commerce, Washington D.C, 1982.

McCartney, M. S., Subantarctic Mode Water. in A voyage of DISCOVERY, M. Angel, ed., 103-119, 1977.

Molinari, R. L., Observations of Eastward Currents in the Tropical South Atlantic Ocean: 1978-1980. J. Geophys. Res., 87, 9707-9714, 1982.

Molinari, R. L., S. L. Garzoli, and R. W. Schmitt, Equatorial Currents at $1000 \mathrm{~m}$ in the Atlantic Ocean. Geophys. Res. Lett., 26(3), 361-363, 1999.

Molinelli, E. J., The antarctic influence on Antarctic Intermediate Water. J. Mar. Res., 39(2), 267-293, 1981.

Ollitrault, M., Y. Auffret, N. Cortès, C. Hémon, P. Jégou, S. L. Reste, G. Loaëc, and J.-P. Rannou, The SAMBA Experiment. Volume 1, SAMBA I, Lagrangian and CTD Data. February 1994 - August 1995. Repères océan No. 12, 1995.

Ponte, R. M. and J. Luyten, Analysis and interpretation of deep equatorial currents in the central Pacific. J. Phys. Oceanogr., 19, 1025-1038, 1990a.

Ponte, R. M. and J. Luyten, Deep velocity measurements in the western equatorial Indian Ocean. J. Phys. Oceanogr., 20, 44-52, 1990b.

Ponte, R. M., J. Luyten, and P. L. Richardson, Equatorial deep jets in the Atlantic Ocean. Deep-Sea Res., 37(4), 711-713, 1990.

Richardson, P. L. and D. M. Fratantoni, Float trajectories in the deep western boundary current and deep equatorial jets of the tropical Atlantic. in New Views of the Atlantic, W. Zenk, R. G. Peterson, and J. R. E. Lutjeharms, eds., Deep-Sea Res. II, 46 (1-2), 305-333, 1999.

Richardson, P. L. and W. J. Schmitz, Deep Cross-Equatorial Flow in the Atlantic Measured With SOFAR Floats. J. Geophys. Res., 98(C5), 8371-8387, 1993.

Schmid, C., B. Molinari, and S. Garzoli, New observations of the intermediate depth circulation in the tropical Atlantic. J. Mar. Res., 59(3), 281-312, 2001. 
Schmid, C., G. Siedler, and W. Zenk, Dynamics of Intermediate Water Circulation in the Subtropical South Atlantic. J. Phys. Oceanogr., 30(12), 3191-3211, 2000.

Schott, F. A., J. Fischer, and L. Stramma, Transports and Pathways of the UpperLayer Circulation in the Western Tropical Atlantic. J. Phys. Oceanogr., 28(10), 1904-1928, 1998.

Schott, F. A., L. Stramma, and J. Fischer, The warm water inflow into the western tropical Atlantic boundary regime, spring 1994. J. Geophys. Res., 100(C12), 24,745-24,760, 1995.

Send, U., C. Eden, and F. Schott, Atlantic equatorial deep jets: space-time structure and cross-equatorial fluxes. J. Phys. Oceanogr., 32(3), 891-902, 2002.

Stramma, L., Geostrophic transport of the South Equatorial Current in the Atlantic. J. Mar. Res., 49, 281-294, 1991.

Stramma, L. and R. G. Peterson, The South Atlantic Current. J. Phys. Oceanogr., 20, 846-859, 1990.

Stramma, L. and F. A. Schott, The mean flow field of the tropical Atlantic Ocean. in New Views of the Atlantic, W. Zenk, R. G. Peterson, and J. R. E. Lutjeharms, eds., Deep-Sea Res. II, 46 (1-2), 279-303, 1999.

Suga, T. and L. D. Talley, Antarctic Intermediate Water circulation in the tropical and subtropical South Atlantic. J. Geophys. Res., 100(C7), 13,441-13,453, 1995.

Warner, M. J. and R. F. Weiss, Chlorofluoromethanes in South Atlantic Antarctic Intermediate Water. Deep-Sea Res., 39(11/12), 2053-2075, 1992. 